\title{
Conceptualising Empowerment, Gender and Quota: The Implications of Women's Leadership Styles at Managerial Positions
}

\author{
Layla Faisal Al-Halwachi
}

Bahrain Polytechnic, Kingdom of Bahrain

\begin{abstract}
Empowerment is a topic which has been subject to a considerable amount of debate in recent years. Not only is there discussion surrounding what empowerment means and encompasses [1], there is also discussion as to how it should be applied effectively [2]. Research in this area indicates that numerous factors impact upon perceptions of empowerment, and it would appear that a combination of intrinsic and extrinsic factors influences the extent to which an individual perceives they are empowered, and even the way in which an individual perceives they are empowered [3]. This work concentrates on perceptions of female empowerment in senior leadership roles and determines that the most critical factors influencing perceptions of female empowerment are derived from individual approaches to leadership and the extent to which a female is supported in their position. Unfortunately, the research demonstrates that the actual situation facing female leaders in the workplace and the extent to which they are empowered is significantly less than the ideal state might wish. Attempts to redress the balance have included discussions surrounding the use of quotas to help empower women [4, 5], and also alternative forms of training and mentoring to help provide women with the necessary techniques and skills to achieve parity in the workplace. Overall the research establishes that there is no single solution to the problem of empowerment. This situation is exacerbated by the chasm between perception and reality, with acceptance of equality at surface level but the practical and factual evidence demonstrating significant levels of inequality. At the close this discussion it is concluded that until these issues are discussed in open forums then it is unlikely that there will be any form of significant change. The research critically examined the effectiveness of possible alternative practical resolutions to improving female presence and representation in senior management levels and the boardroom, and investigated the effectiveness of quota as a proposed resolution to level the playing field in the business world. Whilst numerous academics have attempted to explain the disproportionately small representation of females in the boardroom, there is an equal and opposite amount of debate which questions whether artificial creation of quotas and female representation will indeed enhance organizational performance. Studies are therefore needed to address this situation. An issue which arises out of this is the need to examine whether deliberately creating greater female representation at senior levels will naturally deliver improved female representation as a consequence of strong female role models, and improved career paths for women. Empirical studies reveal that gender equality enables and facilitates improved corporate performance [6]. This literature review therefore focuses on important factors that act as barriers which inhibit gender equality in the corporate boardroom, and critically reviews various theories, concepts and models to elucidate underlying conceptual aspects leading to a better understanding of those factors.
\end{abstract}

\section{Introduction}

In recent years' women all around the world have experienced an exponential increase in participation in economic activities. They have been able to join the labour force and take up positions in various areas that were previously only considered appropriate for men. Despite the many obstacles on this journey and contribution to the labour force, such as disbarment from specific professions and the requirement for male endorsement
[7] women have continued to fight for recognition of their economic contribution to the labour force.

Women have effectively been contributing since the dawn of human history to the economic sphere via their unpaid labour and now is the time for them to take their paid place in the labour market. The chapter concentrates on exploring the concept of 
empowerment, its role in organisations and the business case for empowering women at a senior level in the labour force. It also explores the correlation between leadership and empowerment and tackles the thorny question of female quotas on executive boards. Finally, it addresses the relationship between female leadership specifically and its impact on organisational growth. Peebles et al [8] reveal that there is a clear business case for gender equality in workplaces which contributes to improved organisational performance; however, the gender representation of women in the boardroom remains disproportionately small. Thus, the overarching aim of this research is to establish how leadership and empowerment are correlated with regard to females in the workforce, and to ascertain whether or not there is a justifiable case for female quotas on executive boards.

This paradoxical situation of perpetuation of gender inequality in workplaces against the interest of firms needs to be addressed in general. Despite a large volume of research into gender inequality in the workplace such research outcomes are still unable to stop the phenomenon of gender discrimination in workplaces and largely ignore the problems pertaining to access to challenging assignments and power [9, 10]. Research outcomes have been produced that have attempted to investigate into some of the invisible artificial barriers that are created by organisations to block women from occupying senior positions at workplaces and studies by scholars have established that despite repeated attempts to address gender equality a number of barriers appear to inhibit equal female representation of the most senior corporate levels.

The outcome of the studies in this area as regards equality in the boardroom creates as many questions as it answers. Whilst numerous academics have attempted to explain the disproportionately small representation of females in the boardroom, there is an equal and opposite amount of debate which questions whether artificial creation of quotas and female representation will indeed enhance organizational performance. Studies are therefore needed to address this situation. An issue which arises out of this is the need to examine whether deliberately creating greater female representation at senior levels will naturally deliver improved female representation as a consequence of strong female role models, and improved career paths for women. Empirical studies reveal that gender equality enables and facilitates improved corporate performance [6, 11]. This literature review therefore focuses on important factors that act as barriers which inhibit gender equality in the corporate boardroom, and critically reviews various theories, concepts and models to elucidate underlying conceptual aspects leading to a better understanding of those factors. Accordingly, this chapter strives to examine three discrete areas pertaining to the rise of women in the workforce and their direct and indirect contributions, viz (i) The concept of empowerment; (ii) the relationship between leadership and empowerment; and (iii) the arguments for and against quotas to enforce empowerment. It is intended that the outcome of this process is a conceptual understanding of the factors which influence female representation at a senior organisational level, and the corresponding interrelation of these factors which are both extrinsic and intrinsic for the women in question.

The discussion concentrates on exploring the concept of empowerment, its role in organisations and the business case for empowering women in the labour force. It also explores the relationship between leadership and empowerment and tackles the thorny question of female quotas on executive boards. Finally, it addresses the relationship between female leadership specifically and its impact on organisational growth, as identified in the existing practitioner studies and research $[12,13,14]$, as this underpins the business case for creating improved gender equality and a pathway for females to achieve senior leadership positions, The overarching aim of this research is to establish how leadership and empowerment are related with regard to females in the workforce, and to ascertain whether or not there is a justifiable case for female quotas on executive boards.

In order to explore the role of women and their relationships with empowerment this chapter aims to explore definitions of empowerment in general, so as to appreciate the differing perceptions of empowerment and also the influence of extrinsic variables such as national culture $[15,16]$. It is further 
suggested by both Pastor [17] and Wright et al., [18] that social and cultural understanding of the term empowerment has evolved over time and thus it is necessary to consider the impact of history on contemporary interpretations of empowerment as this will affect the way in which organisations deploy empowerment activities within their internal frameworks. Having considered empowerment in a broad contextual setting, this literature review will then focus on three discrete areas. First it considers empowerment in the field of business and management and the business case for empowerment leading to enhanced organisational productivity; secondly, it determines the norms and forms of empowerment within organisations and how women in the workforce react to these. Thirdly, it evaluates how women relate to empowerment in the organisational context in terms of leadership, or to express this directly, if women are found to have a different style of leadership, how this relates to organisational productivity and success and thus whether this supports or undermines the business case for female quotas.

Having explored the factors which underpin empowerment, this study will seek to focus on one aspect of empowerment, represented in the following question: Which factors truly empower and undermine women in the boardroom with regard to the use of quotas? This will comprise an examination of the attitudes and approaches of senior female managers towards the use of quotas in order to determine if women feel that these quotas are an empowering factor, or whether in fact they are an inhibiting factor and are counter-productive to overall female empowerment. Initial indications are that senior female managers and leaders experience slow progress through the glass ceiling into corporate boardrooms [19]. It seems that they face many challenges on this journey including casual and unintended sexism [4]. Self- inducing factors such as difficulties with self-confidence [5], and the fact that in many workplaces the skill-sets which are natural for women are not as widely recognised as being of value. For example, women are often attributed with having a higher level of emotional intelligence and stronger communication skills [20]. As these skills are not necessarily tangible they can be dismissed as secondary in an organisation which is driven by quantifiable metrics. It is anticipated these factors play a role for women who are experiencing difficulties in gaining empowerment, and attaining a place of recognition within organisations without the distorting effect of quotas. By understanding the true nature of the factors which appear to inhibit female empowerment in the boardroom and in the workplace in general it will be possible to address the root causes. The value of this is an increase in economic participation which allows women, organisations and even national economies to achieve greater economic potential.

\section{What is Empowerment?}

The first and most obvious question to pose in this discussion is "what is empowerment?" It is very easy for the term to be used as a blanket or 'catch-all' phrase to describe a scenario whereby an individual or group of individuals is given a form of power to use within a certain situation. However detailed analysis of the phrase empowerment reveals not only are there are multiple forms of empowerment, there are also multiple definitions and multiple variables which affect perceptions of empowerment. To break this simple question of "what is empowerment?" into its constituent parts it is sensible to consider each of these aspects in turn.

It is necessary to understand the different constituent parts of empowerment and it is sensible to consider each of these parts in turn. Therefore this segment of the discussion will relate to the main constituent parts of the term empowerment which include (1) definitions of empowerment (2) forms of empowerment; (3) Disciplines of empowerment.(4) Context of empowerment [21]; (5) the variables which affect perceptions of empowerment. It is posited that, these aspects are discussed and critically analysed by researchers in general in the literature pertaining to empowerment. A critical review of these aspects of empowerment is expected bring out the differences and the commonalities persisting in the literature leading to a better understanding of the underlying concepts particularly in regard to women's empowerment at the corporate board level.

\section{Definitions of Empowerment}

Nykodym et al. [21] explain that, conceptually, the notion of general employee 
empowerment moved into mainstream debate in the early 1990s and was principally concerned with principles of HRM (Human Resources Management) and the perceived and tested benefits deriving from involving employees in their working environment. Pastor [22] argues that the term "empowerment" is used too loosely and suggests that it is "bandied about" without due regard for its meaning or any understanding by those who are impacted by it. She further suggests that empowerment is in fact best understood as a process of evolution given that it involves a transition or transference of implied power from one source of authority to another (1996). The implications of this are that some organisations are seeking to implement empowerment initiatives as a "tick box" exercise because they fail to appreciate fully that empowerment is embedded in organisational culture and is not a formulaic process [23]. It is suggested that such an approach is almost doomed to failure because without a clear understanding of what organisation hopes to achieve through empowerment it will not be possible for them to implement any such initiatives successfully [4]. Moreover, Healy et al. [24] assert that, as the creation of a culture of empowerment is an organic process which takes time, effort and resources to generate, it is unrealistic to benchmark the process and define it with rigidly enforced timescales. Indeed, as empowerment and organisational culture are the direct result of leadership style and organisational impetus, this creates a situation whereby the attempts to impose empowerment are at best lacklustre.

King-Duvall [25] broadly concurs with the findings of Pastor [22], proposing that empowerment is used too frequently as a term which should be correctly described as a synergised process. She argues that empowerment as a concept has as much to do with personal development and the provision of tools in order for employees and individuals to achieve that journey within the context of organisational development at a holistic level. Specifically she refers to the concept of the knowledge organisation [25] and the necessary conditions for empowerment. She summarises these as being (i) freedom to act; (ii) commitment; and (iii) collaboration, with the main thrust of her argument being that, unless these conditions exist for the individual and within the cultural context of the organisation, then empowerment as a change agent cannot occur. It can be surmised from her line of reasoning that, in combination with Pastor's reasoning, empowerment is not a static event nor a discrete condition but a continuous process or state of mind.

Chamberlain [26] raises the point that the term "empowerment" is regularly deployed in social science contexts, and amongst medical practitioners and educators as they assert that their clients or pupils are "empowered". It is become even more popular in recent years amongst social sciences practitioners as they strive to "empower" their clients in order that they may take control of whatever situation they were not previously in control of. Chamberlain [26] conducted research into cross-national understanding of the term empowerment and discovered that not only was there confusion and misunderstanding at a localised level, at a global level the term "empowerment" was simply repeated in English in the vain hope that the concept would be understood. In her cross-national study Chamberlain [26] found that there are in fact 15 factors which contribute towards a holistic definition of empowerment and these range from the most fundamental "having decision-making power", through to the far more sophisticated "being able to change others' perceptions of one's capability and competency to act" [26]. Arguably the more subtle definitions towards the latter end of the list are in fact more useful in understanding diverging perceptions of empowerment. Simply having decisionmaking power does not de facto lead to the ability to use it, as the remit of decisionmaking may in fact be very small and localised, for example deciding the order of work for one day. At the other end of the scale, being able to influence others to believe that an individual is capable of wielding power on a larger scale is far more useful to the individual in question [27], and thus it can be asserted that empowerment is not a discrete condition, but rather a malleable range of perceptions. It is further asserted by Bartunek and Spreitzer [28] that there can be differing perceptions of empowerment within a single social construct. For example, a front-line manager within a large organisation may have a large remit of power at a local level, with responsibility and accountability for their team of employees, but in the wider scale of the organisation, for 
example their ability to implement strategic direction, they have absolutely no power at all. This further supports the view that empowerment is not only subjective but also contextual. Indeed, an individual can believe they have power at a local level, and this can be enough to satisfy them and best practice principles of HRM; however this level of empowerment which is suitable for one individual may in fact be unsuitable for another [22].

Cook [29] expands upon this theme, pointing out that perceptions of empowerment vary from one contextual or cultural setting to another, a view which is shared by Chamberlain [26]. The implications of this from the literature and understanding empowerment in a cross-national context are significant, as this demonstrates that it is imperative to understand the variables which influence perceptions in the first instance in order to create a holistic understanding of what empowerment may mean to different individuals. Denham-Lincoln et al. [2] expand upon this theme in their work, The meaning of empowerment: The interdisciplinary etymology of a new management concept. They argue that, even before it is possible to understand perceptions of empowerment in a cross-national context, it is first necessary to understand them at a localised level in order to appreciate how and why empowerment adds value to an organisation and provides a foundation for growth. Although Beach [30] asserts that employee empowerment is imperative organisational growth, and therefore it should be incorporated within organisational culture, Denham-Lincoln et al. [2] argue that this is a broad brush approach which fails to acknowledge the idiosyncrasies and intricacies of empowerment as a localised level. In short they concur with Chamberlain [26] and observe that because so many variables influence perceptions of empowerment, to create a holistic definition it is necessary to begin from the bottom-up and align this understanding with the topdown view.

Other areas of HRM literature widely espouse the value of two-way communication, and Denham-Lincoln et al. [2] assert that this is imperative in order to understand the level of empowerment which individuals require in order to feel that they actually have empowerment. This subtle distinction between transfer of power and perception of power creates a scenario whereby an individual feels that they are empowered. To provide an example of this within an organisational context, a person can have power within the organisation by dint of their role, for example if they are a manager who attracts a level of power as they have some degree of authority. However, as noted by Lee and Koh [31] and King-Duvall [25], simply because the role attracts power this does not necessarily mean that the individual has power, as power and respect are two sides of the same coin. This notion is widely explored in leadership literature [32] and will be touched upon later in this work. The implications of this from an organisational perspective are that the individual is then placed in a very awkward position whereby they have notional power because of their individual's role but in practice those who should respect them do not, meaning that their power is largely undermined. Referring back to the variables which influence empowerment as discussed by Chamberlain [26] For instance, an individual may have the "decision-making power", but not be able to change others' perceptions of one's capability and competency to act" [26] thus it may appear that the individual is empowered, but in reality they are not, in fact, empowered. To expand upon this notion, and specifically in the range of female empowerment and the notion of the "poisoned chalice" discussed by Ryan et al. [33], a female in a position of power within an organisation can have notional power because of their role, but limited actual power because they are unable to change others' perceptions of their capability. In this instance it is argued that they are not in fact empowered because at best they have pyrrhic power which is of virtually no use, making them a figurehead in the organisation. Ultimately this discussion can be linked to the discussion in relation to quotas, as under this understanding of empowerment, simply giving women a position on the board to balance gender quotas will be more damaging than it is useful. This is because there are different perceptions of empowerment and the more subtle understanding and the ability to influence others represent true empowerment as opposed to notional empowerment.

According to Thomas and Velthouse [34], the term "empowerment" embraces a wide range of concepts in the sphere of societal 
emancipation. The literal definition of empowerment is "(1) to give or delegate power or authority" or "(2) to enable or permit" [35]. This definition implies that power is held by an individual or a group of people and given (freely or otherwise) to others. Specifically in this context the inference is that power and authority are held by men and are given by them to enable or facilitate female participation on an equal economic and societal footing. However a critical examination of the term "empowerment" in the context of gender empowerment and working environment reveals innumerable subtle variations upon the interpretation [36, $37,38,39,40]$. The root cause of these varied interpretations appears to rest on a number of factors such as the perspective of the commentator [41], prevailing societal attitudes and beliefs [42] and responses to extrinsic stimuli [43]. The challenge of course, is appreciating the influence of one variable upon another, and thus the personal interpretation of the term "empowerment" within a discrete context. Thus it is useful to examine several of the prima facie definitions of empowerment in order to reach a holistic understanding of its meaning which can be carried forward in this work.

Kabeer [38] reveals that there are a number of consistent themes under the banner of empowerment including inter alia, agency, resources and achievements. According to Kabeer [38] these form a symbiotic relationship which encourages women to greater heights of economic and societal achievement in the workforce. Kabeer [38] also explains the significance of the reciprocal relationship between economic and societal advancement based on the premise that economic power inherently conveys societal power. The simple rationale for this is that women who have a personal income are not dependant on men for financial support, the extension of this being that financial support conveys personal freedom. However, Khalil et al [44] and Hamid and Jabbari [45] both suggest that this approach is entirely over-simplistic and that interpretations of empowerment are multilayered at the macro, meso and micro perspectives. They posit that empowerment in the employment relationship is guided by the psychological contract which is in itself linked to societal perspective and interpretations.
The distinction between the perspectives of Khalil et al [44] and Hamid and Jabbari [45] is found in the perceived power which is generated from organisational learning. Khalil et al [44] holds that a power which must logically precede economic power is that of intellectual or educational power, as without education and knowledge, even at a localised level, it would be impossible to prosper in an economic context. Thus it is suggested by Khalil et al [44] that education and knowledge operate at macro, meso and micro levels as guided by the specific on the individual in question. In contrast to this, Hamid and Jabbari [45] suggest that empowerment in an employment context is a complex reciprocal relationship regardless of the gender of the individual. They reveal that empowerment is the culmination of " $a$ sense of competence, [a] sense of being effective, [a] sense of being valuable, [and] autonomy and trust". These factors apply regardless of the gender issue at a macro level, however granular interpretation of empowerment at a micro level is then guided by the conflicting notions of personal confidence and belief set against societal expectations. This can be correlated with the interpretation of Khalil et al [44] and the determination that personal empowerment is connected with knowledge, and from knowledge stems confidence and self-belief. However, the interpretation of Hamid and Jabbari [45] serves as an extension to this and illustrates the multiple dimensions of empowerment for females who can be confident in one area of their personal lives, but far less so in their professional ones largely thanks to the extrinsic influences of social expectation [40,46,47]. The forgoing arguments show both converging and diverging perspectives proposed by researchers providing alternative views about women empowerment. These perspectives while finding support in multiple in multiple contexts provide a basic understanding of the need to find appropriate concepts that could be applied to the context of this research. Further to discussing the contradictory perspectives proposed by researchers, the following sections investigate other factors and theories proposed by other researchers.

\section{History and Development of Female Empowerment}

Nykodym et al. [21] explain that, conceptually, empowerment moved into mainstream debate in the early 1990s and 
was principally concerned with principles of HRM (Human Resources Management) and the perceived and tested benefits deriving from involving employees in their working environment. Pastor [22] argues that the term "empowerment" is used too loosely and suggests that it is "bandied about" without due regard for its meaning or any understanding by those who are impacted by it. She further suggests that empowerment is in fact best understood as a process of evolution given that it involves a transition or transference of implied power from one source of authority to another (1996). The implications of this are that some organisations are seeking to implement empowerment initiatives as a "tick box" exercise because they fail to appreciate fully that empowerment is embedded in organisational culture and is not a formulaic process [23]. It is suggested that such an approach is almost doomed to failure because without a clear understanding of what organisation hopes to achieve through empowerment it will not be possible for them to implement any such initiatives successfully [4]. Indeed, as empowerment and organisational culture are the direct result of leadership style and organisational impetus, this creates a situation whereby the attempts to impose empowerment are at best lacklustre.

King-Duvall [25] broadly concurs with the findings of Pastor [22], proposing that empowerment is used too frequently as a term which should be correctly described as a synergised process. She argues that empowerment as a concept has as much to do with personal development and the provision of tools in order for employees and individuals to achieve that journey within the context of organisational development at a holistic level. Specifically she refers to the concept of the knowledge organisation [25] and the necessary conditions for empowerment. She summarises these as being (i) freedom to act (ii) commitment and (iii) collaboration, with the main thrust of her argument being that, unless these conditions exist for the individual and within the cultural context of the organisation, then empowerment as a change agent cannot occur. It can be surmised from her line of reasoning that, in combination with Pastor's reasoning, empowerment is not a static event nor a discrete condition but a continuous process or state of mind.
Chamberlain [26] raises the point that the term "empowerment" is regularly deployed in social science contexts, and amongst medical practitioners and educators as they assert that their clients or pupils are "empowered". It is become even more popular in recent years amongst social sciences practitioners as they strive to "empower" their clients in order that they may take control of whatever situation they were not previously in control of. Chamberlain [26] conducted research into cross-national understanding of the term empowerment and discovered that not only was there confusion and misunderstanding at a localised level, at a global level the term "empowerment" was simply repeated in English in the vain hope that the concept would be understood. In her cross-national study Chamberlain [26] found that there are in fact 15 factors which contribute towards a holistic definition of empowerment and these range from the most fundamental "having decision-making power", through to the far more sophisticated "being able to change others' perceptions of one's capability and competency to act" [26]. Arguably the more subtle definitions towards the latter end of the list are in fact more useful in understanding diverging perceptions of empowerment. Simply having decisionmaking power does not de facto lead to the ability to use it, as the remit of decisionmaking may in fact be very small and localised, for example deciding the order of work for one day. At the other end of the scale, being able to influence others to believe that an individual is capable of wielding power on a larger scale is far more useful to the individual in question [27], and thus it can be asserted that empowerment is not a discrete condition, but rather a malleable range of perceptions. It is further asserted by Bartunek and Spreitzer [28] that there can be differing perceptions of empowerment within a single social construct. For example, a front-line manager within a large organisation may have a large remit of power at a local level, with responsibility and accountability for their team of employees, but in the wider scale of the organisation, for example their ability to implement strategic direction, they have absolutely no power at all. This further supports the view that empowerment is not only subjective but also contextual. Indeed, an individual can believe they have power at a local level, and this can be enough to satisfy them and best practice 
principles of HRM; however this level of empowerment which is suitable for one individual may in fact be unsuitable for another [22].

Cook [29] expands upon this theme, pointing out that perceptions of empowerment vary from one contextual or cultural setting to another, a view which is shared by Chamberlain [26]. The implications of this from the literature and understanding empowerment in a cross-national context are significant, as this demonstrates that it is imperative to understand the variables which influence perceptions in the first instance in order to create a holistic understanding of what empowerment may mean to different individuals. Denham-Lincoln et al. [2] expand upon this theme in their work The meaning of empowerment: The interdisciplinary etymology of a new management concept. They argue that, even before it is possible to understand perceptions of empowerment in a cross-national context, it is first necessary to understand them at a localised level in order to appreciate how and why empowerment adds value to an organisation and provides a foundation for growth. Although Beach [30] asserts that employee empowerment is imperative organisational growth, and therefore it should be incorporated within organisational culture, Denham-Lincoln et al. [2] argue that this is a broad brush approach which fails to acknowledge the idiosyncrasies and intricacies of empowerment as a localised level. In short they concur with Chamberlain [26] and observe that because so many variables influence perceptions of empowerment, to create a holistic definition it is necessary to begin from the bottom-up and align this understanding with the topdown view.

The fact that the visualisation and operation of empowerment (and power itself) vary across cultures is something that has been widely acknowledged in organisational studies. Although these frameworks acknowledge gender (i.e. masculinity and femininity) as a key aspect of power relations in organisational settings and management communications, their correlative use in the research of glass ceiling scenarios has not been extensive to date. The power distance, uncertainty avoidance, masculinity/ femininity, individualism/ collectivism, and long/short term orientation were designed to facilitate cross-cultural understanding of the weighting of each consideration for individuals and group. The important point about this in the context of this research is that these are social perspectives, based on societal considerations, but intended for application in organisation settings. This may be illustrated through reference to the two most relevant indices, i.e. power distance, and masculinity/femininity. The latter denotes '...the degree to which cultures foster or maintain differences between the sexes in work-related values'. Meanwhile, power distance in Hofstede's analysis explains '..the degree to which people expect power and authority to be distributed and expressed equitably or inequitably'.

Other areas of HRM literature widely espouse the value of two-way communication, and Denham-Lincoln et al. [2] assert that this is imperative in order to understand the level of empowerment which individuals require in order to feel that they actually have empowerment. This subtle distinction between transfer of power and perception of power creates a scenario whereby an individual feels that they are empowered. To provide an example of this within an organisational context, a person can have power within the organisation by dint of their role, for example if they are a manager who attracts a level of power as they have some degree of authority. However, as noted by Lee and Koh [31] and King-Duvall [25], simply because the role attracts power this does not necessarily mean that the individual has power, as power and respect are two sides of the same coin. This notion is widely explored in leadership literature [32] and will has been touched upon earlier in this research. The implications of this from an organisational perspective are that the individual is then placed in a very awkward position whereby they have notional power because of their role but in practice those who should respect them do not, meaning that their power is largely undermined. Referring back to the variables which influence empowerment as discussed by Chamberlain [26] the first concept was "having decision-making power", but it is argued that because the more sophisticated element of "being able to change others' perceptions of one's capability and competency to act" [26], is also present, ergo the individual is not, in fact, empowered. To expand upon this notion, and specifically in the range of female empowerment and the 
notion of the "poisoned chalice" discussed by Ryan et al. [33], a female in a position of power within an organisation can have notional power because of their role, but limited actual power because they are unable to change others' perceptions of their capability. In this instance it is argued that they are not in fact empowered because at best they have pyrrhic power which is of virtually no use, making them a figurehead in the organisation. Ultimately this discussion can be linked to the discussion in relation to quotas, as under this understanding of empowerment, simply giving women a position on the board to balance gender quotas will be more damaging than it is useful. This is because there are different perceptions of empowerment and the more subtle understanding and the ability to influence others represent true empowerment as opposed to notional empowerment.

\section{Constructs and Theories of Female Empowerment}

Having established that female empowerment is a complex concept with multi-layered and overlapping dimensions; the discussion now turns to the existing theories and constructs of female empowerment as distinct from general notions of empowerment. In order to appreciate the extent of female empowerment in a given situation it is necessary to provide some form of metric which can be used to benchmark the respective levels of female empowerment in comparison to male empowerment, and also to illustrate the extent of increased female empowerment where appropriate. Early adopters of the subject of female empowerment such as Mason [48] and Mayoux [36,49] readily identified the fact that whilst females may not be openly empowered in the workplace [50] they are able to gather power from other sources such as domestic economic and resource control and family matters. Subsequent writers in this area identified that other markers of female empowerment include freedom of movement [51] and education and intellectual property or knowledge [52, 53]. However the level of discussion and debate in this area makes it apparent that there are no straightforward approaches to capturing and measuring the dimensions of female empowerment, largely because interpretations of the societal indicators are highly subjective.
In an effort to overcome this challenge, Kabeer [38] proposed a tri-partite approach which could be adopted to assess empowerment at multiple levels, viz, agency, resources, and achievements. Her rationale for this approach was that these dimensions are readily transferrable can be grounded in prevailing norms, socio-economic customs and cultures thus providing a like-for-like comparator of female empowerment. Scholars such as Mayoux [49] and Metcalfe [54] concur that these dimensions share common interpretations across the existing empirical and conceptual frameworks and literature, and thus have the benefit of drawing together alternative perspectives on female empowerment to provide a holistic representation of the situation of women, especially in the Middle East. It will be recalled that Kabeer's [38] approach is grounded in the de facto assumption that increased agency bears a direct correlation to increased economic and thus societal freedom. It will also be noted that Khalil et al [44] and Hamid and Jabbari [45] regarded this view as overly simplistic, although having some merit. To recap, Kabeer [38] proposed a triad of factors which would contribute to empowerment, specifically (i) improved education; (ii) access to improved employment prospects (that is to say work outside of the agricultural sector); and (iii) political representation. She observed that whilst in developed economies these three factors were taken as given, in emerging economies these were the three key indicators of female empowerment. Both Khalil et. al. [44] and Hamid and Jabbari [45] suggested that whilst Kabeer's [38] approach offered a strong foundation for examining the notion of female empowerment in emerging economies, once a nation had experienced grassroots female empowerment with a limited number of role models, then it was necessary to examine more complex factors to appreciate why other females were unable to follow in the footsteps of these trailblazers. Thus it would seem that an extension of the Kabeer [38] framework which embraces wider socio-economic influences would provide greater clarity in this area, and would help to provide the foundation for wider understanding of factors which influence societal perceptions of female empowerment. 
Gibbon [55] suggests that there are in fact a far greater range of factors which should be considered when assessing female empowerment, as figure 2 overleaf illustrates. She embraces the fact that many of the markers of female empowerment are challenging to identify and compare, and instead opts to demonstrate the linear and cross-functional impact of the variables which lead to a meaningful assessment of female empowerment. In her framework illustrated in figure 2 she expands on the ideas discussed by Kabeer [38], and highlights the importance of pre-existing historical and societal constructs and beliefs. In particular she focuses on the social, political, economic and legal status of women in society, demonstrating that two women with similar personality traits and opportunities but born and brought up in entirely different social contexts can have very different experiences of empowerment. She further elucidates in her study that these factors can have an incremental or cumulative effect building up to a complex set of influencing elements which determine how women respond to their external environment as regards their demands and expectations of empowerment.

Gibbon's [55] work pre-dates that of Kabeer [38] and particularly concentrates on the experiences of females in challenging socioeconomic circumstances, examining the effect of specific local conditions upon the females within her test group to identify their perceptions of and reactions to empowerment within what would otherwise be regarded as constrained circumstances. She finds that even in difficult circumstances, the vast majority of females strive to improve their situation and to acquire some form of power and personal control over their lives and incomes. She posits that as a result of this, prevailing environmental conditions affect women in a range of socio-economic circumstances.

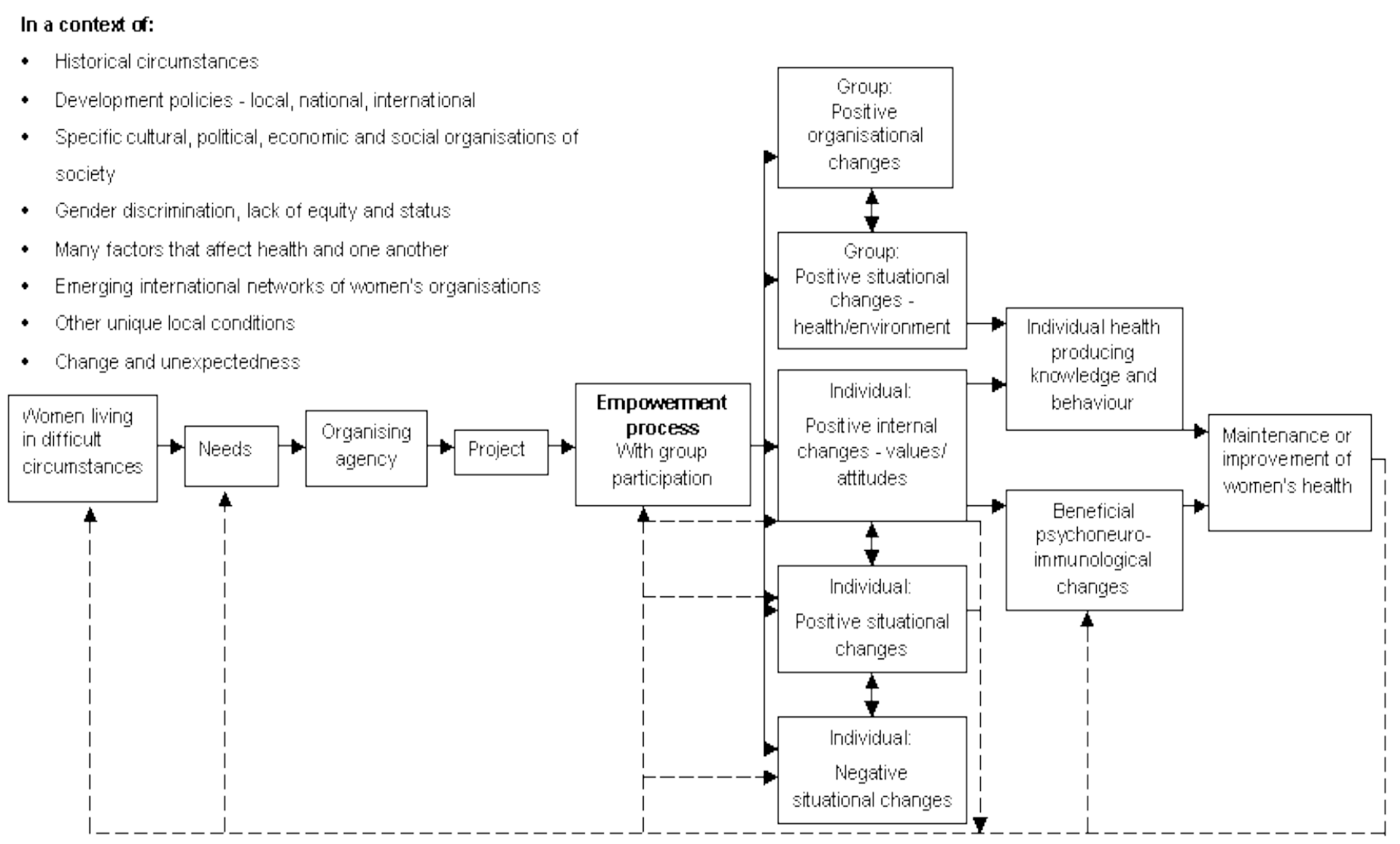

Figure 1: Factors affecting female empowerment

(Source: Gibbon, [55])

Gibbon [55] posits that ultimately improved female empowerment, even for women living in socially challenging environments, has a positive impact on female health and welfare. She further argues that in turn, positive female health helps women to overcome challenges they may face in other areas of their lives as a consequence of extrinsic and thus non-controllable factors. The result being a self-perpetuating cycle of steadily improving levels of female empowerment. The advantage of this model is that it embraces the fact that externalities impact heavily on female empowerment, and it also 
acknowledges the complex correlations between the variables. The challenge is that it can only be applied in a fixed context in order to accurately capture the influences on female empowerment.

\section{Forms of Empowerment}

The division is observed during the review of the literature to date which has established that there is a dichotomy between women who feel genuinely empowered and those who do not. Genuinely or truly empowered women are able to achieve their goals and objectives, fully supported by society and their organisation. This can be described as "true empowerment". On the other hand, "notional empowerment" is derived from the existence of a senior employment role which by dint of the role should confer power upon the individual who holds it, but in fact fails to do so in any meaningful way. The latter is particularly discussed by academics such as [56] and Kumra and Vinnicombe [57] who argue that women can acquire senior positions of power within organisations but fail to actually accrue the same level of power and respect which would be conferred upon a man in the same organisational position. Thus, notionally a female is empowered in the workplace, but in reality she is not able to make her voice heard. Perspectives on these definitions are discussed below.

\section{True Empowerment}

Amalgamating the work of Pearson and Chatterjee [58], Pastor [22], Logan et al. [17] and Manyard et al. [59] it is suggested that true empowerment represents a situation whereby the individual perceives that they have control and, as an adjunct to this others around them also perceive that they have decision-making authority and control, meaning that the two perspectives of empowerment within the organisation are in alignment. Arguably the result is true empowerment and authority, regardless of the level within the organisation, and this is effective at improving organisational profit and efficiency as well as supporting the selfesteem of the individual in question.

The crucial point to observe from the notion of true empowerment is that everyone connected to the individual with empowerment also believes that the individual in question is empowered and that they are respected and their decisions are revered. This makes the decision-making process far easier, and also means that when decisions are taken by the empowered individual they are quickly implemented, which has clear benefits to all stakeholders concerned.

\section{Notional Empowerment}

Notional empowerment on the other hand is drawn from the work of Chamberlain [26] Denholm-Lincoln et al. [2] and Khalid et al. [60], who observe that it is entirely possible for an individual to believe that they are empowered relative to their own perspective, but in fact they have a very limited remit of power. This can be further subdivided depending upon whether the individual actually wants to be empowered, as there is a fundamental assumption in the literature that this is the aim and objective of all individuals. There is certainly evidence to suggest that some people are quite happy with a very low level of empowerment which only affects their immediate vicinity, for example their ability to decide what to do when a day-to-day basis [61]. Thus, where others seek power at a higher level, and the ability to influence and control a large number of individuals, some people are simply not concerned with this aspect. Bringing this back to the discussion in regard to notional empowerment, the evidence presented by Khalid et al. [60] suggests that a role within an organisation, for example a middle management role, has notional power attached to it because of the structure of the organisation. However if the individual within the role has empowerment, perhaps because those who work for the individual see that individual has insufficient experience and capability, this will result in the subtle undermining of empowerment authority in much the same way as Ryan et $a l$. [62] discuss the notion of the "glass cliff".

This leads to the situation whereby the role has empowerment that the individual does not, and this divisive situation creates a very unpleasant atmosphere and situation for the individual concerned if they are aware of the fact that, despite their role, they are incapable of influencing others to do their bidding. Once again this returns to the subtle definition proposed by Chamberlain: if it is not possible to convince others that an individual is capable of performing the role then no matter what they may wish to believe, they are not truly empowered. 


\section{Variables Which Influence Perceptions of Empowerment}

As previously noted a critical review of the
literature indicates that there are 15 variables which influence perceptions of empowerment. These are summarised in the table below with their supporting evidence and rationale.

Table 1: Variables influencing perceptions of empowerment

\begin{tabular}{l|}
\hline \multicolumn{1}{|c|}{ Variable } \\
Holding decision-making power; the \\
ability to make and take decisions which \\
are respected
\end{tabular}

Access to information and necessary resources

\section{Chamberlain [26] and Denholm-Linidence}

make meaningful decisions is fundaln et al., [2] assert that holding the ability to that an individual lacks the ability to make coherent decisions, is inherently undermines the notion of empowerment and is directly correlated to the perception of confidence and capability. Further to this Gajjala et al [63] suggest that making decisions which are respected or understood is also integral to empowerment. Again this is a subtle distinction because an individual who is capable of making and following through unpopular decisions for the right reasons is considered as having a high degree of empowerment. As an addition to this, Nykodym et al. [21] posit that decision-making powers are contextual and it is possible for an individual to be capable of making decisions in one context and not in another. This does not detract from the overall notion of empowerment and it is therefore important to consider critically the prevailing context of the decision-making process.

There is an old saying that "knowledge is power", and debarring access to information undermines the ability to take decisions. Roberts [64] believes that decision-making in a vacuum is a dangerous scenario, and although many organisational leaders are forced to make decisions with imperfect information because of the dynamic nature of markets, being able to capture as much information as possible prior to having to make the decision is a fundamental aspect of empowerment. Rodrigues [65] asserts that restricting information to individuals in their "best interest", which commonly occurs in many patriarchal societies, is highly damaging, although this does not detract from the fact that this situation perpetuates itself. Breaking this chain is considered to be essential [63]. In short, there is no disagreement as to the fact that access to information is critical to empowerment. Interestingly [66] assert that the ability to interpret information once it is being gathered because the individual has the necessary tools is in fact a more useful indicator of whether or not the individual is empowered. For example there is little point in presenting an individual with a range of complex statistical data if they are unable to interpret it.

Having the ability to choose from a range of scenarios (i.e. not being presented with dichotomous choices)

\section{Confidence or assertiveness}

Chamberlain [26] indicates that meaningful choice is far wider than being presented with dichotomous options (that is to say yes/no or either/or alternatives). Individuals who are empowered have the ability, opportunity, means and motive to choose from a range of variables depending on the context and circumstances. Individuals who are not empowered are presented with a truncated list of options. She believes that this is not empowerment or meaningful choice. Anderson and Eswaran [67] argue that there are some limited occasions when dichotomous options are the only options available, but in the main choosing from a range of scenarios is an indication of true empowerment.

Confidence or assertiveness is considered as essential to empowerment because they are directly related to the ability to make and take decisions; however there are subtle distinctions between the two and it is interesting to note that in certain societal settings there is a fine line between confidence and arrogance, and similarly between assertiveness and aggressiveness. These personality traits are valued in some people are but others consider as negative aspects of personality, particularly in the case of women in male-dominated organisations who would personally consider themselves assertive, but are in fact regarded as being aggressive [62]. This explains why the perception that others hold of the individual helps to create the difference between true and notional empowerment.

A personal belief that it is possible to make a difference

It was interesting to observe that, on a cross-national basis, personal belief that it is possible to make a difference is highly empowering. According to Shapira et al. [60] this is because it engenders a sense of control, and encourages an individual to believe that they are capable of managing their own destiny, even if it is only on a localised scale. Believing that it is possible to make a difference is often associated with not-for-profit organisations and individual growth and development [68]; however a personal belief in localised control is a consistent theme in the literature, regardless of whether it relates to day-to-day activities in the workplace, or a wider social context. In essence it reflects personal hope which is an extremely powerful motivator [69].

The ability or opportunity to think critically Collins [50] points out that without the opportunity or ability to think critically; simply doing as one is told is not an empowering situation, even if the individual has a notionally powerful role. Arguably this is linked to the notions of confidence and competence, and where necessary the ability to take decisions without recourse to higher authority. Blackburn and Jarman [70] propose that the ability to view things from a different perspective and contrast alternative solutions is also inherent in the notion of empowerment. This is because a single line of thinking is likely to be a direct reflection of what an individual has been told and therefore they are not empowered; they are merely a mouthpiece or a puppet for another individual. Whilst this assertion may be quite strident, there is certainly some merit in this statement, if only for the fact that different circumstances require different solutions and therefore the ability to consider options is an indication of critical thinking. 

Freedom to express emotions and This is a social construct and although polite society demands that individuals do not opinion express overt anger when it is not appropriate, freedom of expression is enshrined in democratic society. Curtailing this freedom is not an empowering situation. The current situation in several countries in the Middle East and resulting Arab Spring are examples of why curtailing freedom of expression in the long-term is disempowering [60].

A feeling of inclusion

Wright et al., [71] believe that isolating individuals directly results in a situation and disempowerment. It is a technique used by children, commonly known as "sending to Coventry", whereby an individual is isolated from social groups. Unfortunately this is expressed as a form of bullying amongst adults in the workplace, and Beale and Hoel [72] believe that isolation is disempowering and inclusion within social networks is empowering because it gives confidence to the individual.

An appreciation of personal rights and freedoms

Understanding the remit of personal rights and freedoms is central to the notion of empowerment as this indicates that the individual appreciates the remit of the power and capability [73]. It should be noted that this is not a bland assertion that "I know my rights", but rather an understanding of how personal capability can be applied within organisational hierarchies or social frameworks in order to maximise level of empowerment. According to Miller and Rayner [74] this should not be confused with attempting to disrupt the social order, but rather enhancing what exists in order to increase collective prosperity for the greater good.

Affecting change at an individual or wider level

Heimovics et al., [75] assert that the ability to effect change is a key indicator of empowerment. He believes this is because not only does the ability to effect change imply a level of control, it also suggests a high degree of confidence and the perception of competence on the part of other individuals or stakeholders. Change management is widely known as a challenging area in its own right, and many individuals have tried and failed to effect change. Although there is no direct evidence of this, there is a potential line of thinking that individuals who are not respected for the confidence capability suffer the ignominy of change management failure because they are unable to engender the support of others which is imperative in change. Potentially this has the capacity to be regarded as notional empowerment if the individual is unable to implement change effectively. In contrast to this it should be acknowledged that there is a wide body of literature which talks about the capability of an individual to change their personal circumstances. Whilst this is acknowledged as being a useful indicator of personal empowerment, this is not the same as organisational empowerment or empowerment in wider society $[76,77]$.

Learning or acquiring skills which have value to the individual (and relevance in the personal context)

One interesting line of thinking relates to the ability of individuals to learn or acquire skills which are relevant to their perceptions of empowerment. This has a limited amount of research; however it is widely acknowledged that attempting to learn skills or tasks which are not enjoyable or not relevant is particularly difficult [67]. Furthermore, it is obvious that certain technical skills are not relevant in particular roles. This being said, so-called "transferable skills" have a great degree of importance in empowerment, specifically leadership capability and the ability to motivate others. It is argued that these directly link to notions of competence and the ability to inspire confidence in others. What is unclear at this juncture is whether these transferable skills are relevant to the individual and the context of empowerment can be taught, or whether they are learnt in a "chicken and egg scenario" based on confidence in personal ability and demonstrable attempts at empowerment in a wider context [78]. Once again this underlines the importance of appreciating the context of empowerment before reaching any conclusions as to its efficacy.

Influencing others, and creating a Barton and Barton [79]; Chamberlain [26]. The discussion relates to the fact that perception amongst others that the individual is capable unless an individual is perceived as having competence, they are not empowered. Evidence is presented in the literature which illustrates that without a perception of confidence or capability then others with higher levels of power will override the individual and take decisions on their behalf [61]. Similarly employees below the individual in question can perceive them as having limited competence, and they can subtly undermine power, by being deliberately difficult or obtuse [67] and working to rule [80].

\begin{tabular}{|c|c|}
\hline $\begin{array}{l}\text { Ongoing personal change } \\
\text { development }\end{array}$ & $\begin{array}{l}\text { Gaunt [81] asserts that the ability to make personal change and development is as } \\
\text { important as the ability to make wider change and development. The rationale for this } \\
\text { is that wider conditions change and unless an individual is capable of adapting in } \\
\text { tandem, they will not remain in power for long. Although tried and tested techniques } \\
\text { for certain aspects can be repeated ad nauseam, as the market changes it will be } \\
\text { necessary to find new ways of obtaining empowerment especially in the face of } \\
\text { globalisation. Therefore the capacity for personal change leading to enhancement of } \\
\text { leadership style should be considered as a more sophisticated factor of empowerment. } \\
\text { Again this represents a gap in the literature which would benefit from further } \\
\text { research. }\end{array}$ \\
\hline $\begin{array}{l}\text { Positive } \\
\text { confidence }\end{array}$ & $\begin{array}{l}\text { It is asserted by Allen [61] that as an individual becomes more empowered, this } \\
\text { directly improves their feelings of confidence and self-worth and helps to create a } \\
\text { positive self-perpetuating cycle of personal improvement, leading to increased } \\
\text { empowerment. Although positive self-image can of course only be engendered by the } \\
\text { individual, this is also to be considered as an advanced aspect of empowerment } \\
\text { potentially linked to the hierarchy of needs in the form of self-actualisation. }\end{array}$ \\
\hline $\begin{array}{l}\text { Overcoming social stigma in context and } \\
\text { breaking down barriers }\end{array}$ & $\begin{array}{l}\text { Abu-Rabia-Queder and Oplatka [82] and Kirton [83] point out that for overcoming } \\
\text { social stigma it is necessary to mention of empowerment, in all of its formats. Even in } \\
\text { societies which are considered as democracies there is a considerable wealth of } \\
\text { evidence which points at social stigma for supposedly unacceptable social norms (refer } \\
\text { to the preceding discussion on the fine distinction between assertiveness and } \\
\text { arrogance). This is of course contextual, however it is also suggested that this directly }\end{array}$ \\
\hline
\end{tabular}


relates to perceptions of competence. At a basic level one example may be the social perception that women are incapable of functioning in leadership roles because they lack the necessary character aspects. There is no empirical proof for this, but it is acknowledged as a widely held social assumption. This would constitute a barrier which must be broken down in the longer term in order to create wider empowerment, or potentially this should be considered the zenith of empowerment at a global level. Certainly further research is required in this area.

Figure 3 consolidates the variables which have been identified and that affect perceptions of empowerment. It can be argued that perceptions play a major role with regard to empowerment. The need to understand perceptions arises because of the fact that prior research has shown the existence of a relationship between perceptions of empowerment and empowerment itself. More importantly, in the context of current research where the focuses on women's access to corporate boardroom level positions it is necessary to recognise the importance of perceptions of empowerment as perceptions are found to lead women to enact certain behaviour for instance leadership. Although, this argument could be considered anecdotal, considering the fact that many researchers have identified perceptions as a phenomenon that affect empowerment it is reasonable to conclude that perception have a role in defining empowerment. However in the context of this research perceptions are considered to be an essential phenomenon that are presumed to be an important factor based on the conclusion of other researchers and investigation into its relationship with empowerment was considered to be beyond the scope of this research as the focus is on other important factors such as women's leadership and quotas.

Further to the discussion on perception as an important factor that influences empowerment it is important to gain knowledge on other phenomenon that have interplay with women's empowerment with regard to their access to their boardroom level positions. In order to understand what other phenomenon interact with women's empowerment it was necessary to examine many of the theories, models, and concepts already established by other researchers. Thus the next section deals with some of the widely referred theories in this area.

\section{The Wider Context of Empowerment}

Empowerment and Employee
Motivation

There is a significant body of knowledge which demonstrates the correlation between employee empowerment and employee motivation, ultimately leading to increased engagement and organisational productivity [61, 5, 84]. Becker and Huselid [69] suggest that there are two fundamental types of empowerment in the workplace: (i) structural; and (ii) psychological. The former occurs as a result of organisational structure and culture, and the state of being whereby it is possible and indeed feasible for employees to become empowered through their work. According to Becker and Huselid [69] four conditions/ factors must exist before the situation of structural empowerment is present. These are opportunity, information, resources and support.

\section{Opportunity}

Arguably the existence of opportunity for empowerment is present in both large and small organisations albeit in different formats. For example, in a large organisation there is typically the opportunity for individual to take responsibility and accountability for a large project, a large department, or a high-profile piece of work. These are all examples of opportunities for empowerment. However in a small organisation opportunities for empowerment would take a different format. For example, within a smaller organisation it is anticipated that because there is a wide range of tasks to be carried out with a smaller workforce then individuals have the opportunity to embrace many different aspects of the business and are empowered to take responsibility for themselves and make a significant difference to the business. The employees often enjoy working for a smaller firm because they feel that there is an opportunity to make a genuine difference. Contrasting these two types of opportunity it can be seen that there are different forms of empowerment relative to the organisational context, and this creates differing perceptions of empowerment. To express this in another example, an individual can be empowered because they have chosen to set up their own small business in a manner which suits the needs of their lifestyle. They can do what 
they like with their business and can accordingly be regarded as wholly empowered even though the business is very small. At the opposite end of the spectrum, an individual can have a very senior position within a large and high profile organisation and can also be considered as empowered because they have control and responsibility for a large budget and a large number of people. Arguably, both of these situations represent examples of empowerment, but it is unfair to suggest that they represent a likefor-like comparison, because extrinsic factors such as organisational context and intrinsic factors such as personal definition of success in empowerment are represented so differently. It is suggested, therefore, that being able to acknowledge such differences is a variable that should be considered when assessing whether or not empowerment has been achieved.

The forging arguments lend support to the inference that opportunities can empower employees but such opportunities need to be exploited to realise the importance of opportunity as a factor that could empower women. However one of the major opportunities that has been brought by governments as an important factor in the process of empowerment of women is the legislation pertaining to quotas. In many countries corporate boardrooms need to have a specified proportion of women representation like in Norway which adopted gender quotas in 2006 and by law and "required all publicly listed companies to increase female representation on their boards of directors to $40 \%$ within two years". This is an important opportunity for women to exploit. Nevertheless, there are fierce arguments opposing the law pertaining to quotas because of the negative effectives caused by quotas as opportunities. For instance many argue that quotas as an opportunity seriously undermine the importance of merits in the corporate boardroom.

\section{Information}

Information is the next aspect which needs to be considered as a structural aspect of empowerment. According to Detert and Edmondson [85] information is an integral aspect of empowerment. This is because without information it is impossible for an individual to make the necessary choices and decisions which would result in a situation whereby they are in control. Without information it is difficult for an individual to understand what they need to do to take control of their own situation. Furthermore, information comprises two aspects of which the first is factual information which is readily available in a codified format [61]. The second aspect is derived from the concept of social capital. In its own way this is far more important, as without the necessary social capital it is usually difficult to gather factual information and even more difficult to make headway within an organisational culture which relies on social transactions [1]. This is difficult enough in Western organisations where social capital is important but it is not imperative in order for an individual to succeed within an organisation. This is because it is possible for an individual to progress up the organisational hierarchy based on merit [86]. However, in many cultures and especially in the Middle East, it is extremely difficult for an individual to progress without the necessary social capital, which is considered a form of information [87, 88]. Indeed, without social endorsement through recommendation, it is all but impossible for even a man to progress up the organisational hierarchy. For a woman it would be exceedingly difficult. Thus it can be suggested that access to information gained through formal and informal channels is a vital aspect of empowerment within such scenarios. In light of discussions in relation to the Arab Spring it is also suggested that when Middle Eastern nations adopted a policy of sending younger nationals overseas for education they did not appreciate that one of the unintended consequences of this would be access to information [87]. For those who have ready access to formal and informal information channels it is easier to gain confidence so that they can be empowered.

\section{Resources}

According to Drake et al. [89] and Ashamalla [90] resources within the context of structural access to empowerment relate to factors such as level of education. It also embraces the skills and techniques necessary to take control of their personal situation whereby they can attain a state of empowerment. For some, access to resources can almost be a happy accident of fate: for example they were able to have the benefit of a good education which included the belief that they are capable of taking a position of 
empowerment and directing personal growth. Putting this within the context of an organisation's culture, access to resources (including information and training) will depend on several factors. These include whether or not an organisation places value on employee training. It has already been established that engagement is a multifaceted concept but this helps to illustrate how it is directly and indirectly linked to organisational and individual development.

\section{Support}

Finally, it is suggested by Conley [4] that the support provided by both line managers within the organisation and the culture of the business itself, are necessary dimensions of structural empowerment. For Conley [4], support includes creating an environment within the organisation where training and skills development is highly valued. This overlaps with concepts such as employee engagement, as providing high levels of training is widely recognised as a best practice technique, not only for increasing the operational capability of organisations but also because it directly results in increased employee engagement. Further to this, Healy and Kirton [91] suggest that supporting individuals in order that they become empowered is beneficial to businesses as it creates employees who are capable of thinking flexibly and dynamically about organisational and customer needs. Potentially this has the capability to create a form of sustainable differential advantage which is competitive. Although challenging to accept, in the first instance, it is suggested that the logical conclusion of an empowered workforce is one of unique and sustainable competitive advantage which has direct parallels with the resource-based view (RBV). This is an entire body of work in its own right, and yet, there is a clear link between empowered employees and resource-adding or enhancing employees who add direct value to the organisation.

Moreover, it could be suggested that there are parallels between the challenges inherent in the RBV, and the challenges which have already been found as inherent in the body of knowledge relating to best practice and empowerment. Both empowerment and RBV initiatives require a specific form of organisational culture whereby organisational leaders are prepared to devolve and delegate responsibility and empower individuals further down the organisational hierarchy. Pastor [22] argues that for many firms and leaders who have become used to power and control this is a painful concept to embrace and therefore they are reluctant to do so, creating a selfdefeating environment. Subsequently in this literature review there will be a discussion of whether it is necessary to have a particular style of leadership in order to encourage empowerment within the organisation. Prima facie it is suggested that this is the case in light of the discussions as regards the RBV because of the fact that an organisation with an empowered culture is one where employees have a high degree of autonomy and control. This also links to best practice concepts of employee engagement and motivation, and yet is acknowledged as being a very difficult state to achieve as evidenced by the fact that so few organisations are happy to embrace the RBV as a strategy.

In tandem with structural empowerment it is necessary to give due consideration to the concept of psychological empowerment as arguably this presents as much of a challenge to an individual as does the lack of structural empowerment. Indeed, de Vos and Meganack [92] suggest that in some respects psychological empowerment is more important than structural empowerment because failure of the individual to appreciate their worth means that they would never take advantage of the opportunities presented to them even if structural empowerment existed within the organisation. According to Becker and Huselid [69] the conditions necessary for structural empowerment include meaning, competence, influence and selfdetermination. In much the same way as structural conditions for empowerment are interrelated, Becker and Huselid [69] advance that the conditions necessary for psychological empowerment are equally interrelated. Understanding their importance to an individual is also critical as arguably this form is the linchpin of what an individual considers to be critical within their own personal understanding of the term empowerment.

\section{Meaning}

"Meaning" in this context relates to the level of importance of individual places on empowerment and what it means to them as 
an individual. For example, if an individual considers personal empowerment to be important to them, then it is suggested by Espino-Rodríguez and Padron-Robaina [93] that they will go to considerable lengths to place themselves in a situation whereby they can be empowered under their own interpretation of the term. This may comprise seeking to climb the corporate ladder and have a position of high-profile responsibility within a large organisation, or whereby. at the opposite end of the spectrum, an individual considers empowerment to be controlling their own destiny by managing their own organisation or lifestyle business on their own terms. Cox et al. [1] argue that both of these definitions of empowerment are entirely valid and the only distinguishing feature between them is the level of meaning which individual places upon it. Howard [32] concurs with this and also suggests that an individual will strive to create a situation where they are satisfying their own meaning of empowerment under the terms of motivational theories. Again motivational theories comprise a body of knowledge in their own right; however they have relevance in this context as meaning will dictate the level of motivation and the factors that underpin it, especially in regards to whether or not an individual places personal influence on high profile individual contributions or they consider they are empowered by working as part of the team.

Some Researcher disagrees with this and suggests that in fact individuals are empowered when they believe that they are able to make a difference in regards to what they do in the workplace. Cox et al. [1] differs, instead concurring with Becker and Huselid [69] and Pastor [22] that meaning and motivation are indistinguishable from one another and overlap when an individual is striving to achieve a state of empowerment. According to de Vos and Meganack [92] the implications of this as regards psychological empowerment are quite significant. They assert that the individual meaning that the person places on empowerment will ultimately determine whether or not they consider it worth the effort, as it is clear from both the evidence and literature that empowerment is not something that is de facto given to an individual but rather to something which individual strives to attain in light of the circumstances, personal beliefs and preferences. As the situation varies from one individual to another (a repetitive theme throughout the body of knowledge relating to empowerment). The meaning is absolutely fundamental to the concept of empowerment, both from a personal and professional perspective. Indeed, goes as far as to suggest that empowerment overlaps between the personal and professional sphere of an individual and if they feel empowered in their personal lives then they will be empowered in their professional lives. Arguably this has parallels, theories of motivation, as they both believe that higher levels of personal motivation are precursors to empowerment because they are the foundation of self-confidence. This is a factor which will also be discussed in more depth below.

\section{Competence}

According to Becker and Huselid [69], competence is integral for empowerment for the simple reason that unless an individual has a degree of confidence in a professional role, whatever that role encompasses, it is unlikely that they will be empowered. This is because without the necessary knowledge and confidence which comes from competence the individual may not feel able to take control of a situation and place themselves in a position of strength with regard to their capabilities and thus potentially stretching their professional opportunities. Competence is of itself a concept which has less than defined parameters as there is a body of research which discusses the notion of "conscious consciousness" and "unconscious consciousness". In brief these discussions relate to the fact that as an individual becomes intimately familiar with the expectations of their role then they reach a stage whereby they can in fact no longer remember how they do what they do. One example of this would be driving, where after many years of practice it becomes second nature, and this of itself instils personal confidence which is self-fulfilling.

Arguably competence is a prerequisite of empowerment because it is slightly ridiculous to suggest that someone without competence in their role would or indeed should be empowered. Certainly this is the subject of debate when high-profile leaders are held up to ridicule when they fail to perform; however it is suggested that unless it was perceived that they had a degree of competence in the 
first instance they would not have been selected for the role [95]. Under this line of reasoning Gerhart [95] suggests that competence is intimately linked with empowerment and is effectively a precursor to the existence of empowerment for an individual. Furthermore, linking this back to the discussions of structural prerequisites for empowerment, competence occurs through knowledge, repetition, and training and development. It is not reasonable to expect an individual to be empowered without the necessary skills and tools to perform their role and they cannot reasonably be expected to gain competence in a role without time, support and training [61]. Therefore it can be asserted that competence falls between structural empowerment in the form of resource, and as a precursor to full psychological empowerment.

\section{Influence}

Influence within the concept of empowerment relates to both leadership style and negotiation style as the ability to lead and negotiate is inherent in empowerment. According to $\mathrm{Hu}$ et al. [96] this is a sensible line of reasoning because leadership and empowerment are closely correlated and a widely acknowledged trait of good leaders is the ability to influence others such that aims, goals and objectives can be achieved [77]. According to $\mathrm{Hu}$ et al. [96] influence also subtly underpins the concept of empowerment because, in order to feel empowered at a personal level, an individual needs to be confident that they have the capability to influence others in order to achieve their own objectives. Although prima facie this can be taken to sound somewhat self-serving, an empowered individuals are those who feel sufficiently confident to take control of the situation in order to drive it in the direction that they wish. Clearly this notion is closely linked with leadership. However, as a caveat to this, Boldman and Deal [77] suggest that care should be taken to ensure that influence within the context of empowerment does not spill over into a dictatorial or excessively authoritarian leadership style which can no longer be regarded as influencing but instead is domineering. It is suggested that the distinction between the two is a fine line which an individual must tread with care.

There is an interesting further line of argument under this principle suggested by
High-Pippert and Comer [97]. They argue that there are different forms of influence, some of which are inherent by dint of organisational position, and thus attract a natural authority although not necessarily respect. For example, an organisation's chairman may be regarded as having influence simply because he or she leads the organisation. According to High-Pippert and Comer [97] and Bass [98] the question of whether or not someone is respected within a position is a matter of individual degree relative to their leadership style. However, it is also possible for individuals to exert influence much lower down the organisational hierarchy because they command the respect of their peers and colleagues. Inherent in this is the presumption that they have a leadership style of their own because they are able to influence others albeit horizontally as opposed to vertically, and it is also implicit that they possess a degree of competence otherwise they would not have gained the respect of others. Alimo-Metcalfe [99] suggests that this type of empowerment is in its own way as valuable as the more obvious levels of empowerment in high-profile leadership positions.

\section{Self-determination}

According to Prichard [100], selfdetermination is the final factor under the umbrella concept of psychological empowerment and this brings together the other three elements. Self-determination is considered to be the personal will and selfbelief that an individual is "good enough" to push themselves forward. The points to note here are that contextual setting selfdetermination is entirely relevant to the individual and is linked to the target(s) that they may or may not set for themselves. Others believe that an individual with a high degree of self-determination has a greater likelihood of reaching a position whereby they consider themselves to be empowered. Self-determination theory is inherently linked to intrinsic motivation and thus it can be seen that there are correlations between influence and self-determination as well as competence and the desire to succeed. It is almost pointless to suggest that there is a wide degree of differentiation between intrinsic motivation and self-determination, although they concur that self-determination is imperative for empowerment as without this an individual would not have the 
necessary confidence or personal belief that they are capable of being empowered. Thus it can be argued that reaching a state of empowerment, regardless of the personal organisational context, requires a high degree of personal motivation.

\section{Empowerment in the Field of Business and Management}

A great deal of literature addresses the topic of empowerment in an organisational context. Both academics and practitioners concur that organisations which are empowered are more successful and have more productive employees who are engaged with the organisation, and, therefore, devote more of their personal resources to achieving organisational aims $[96,1]$. the positioning of empowerment within the field of organizational studies, and HRM links the concept closely with organisational and leadership success.

Interestingly, Pearson and Chatterjee [58] adopt a subtly different stance to the interpretation of empowerment in the field of business and management and argue that it should not be considered as a process of purely individual development, but one of group or unit development. As such they adopt the theme of organisational cultural requirements voiced by King-Duvall [25] but broaden the context of its application to embrace the need to change organisational mind-sets on a collective basis. As such, they concur that empowerment is not effective as a "top-down" process, but rather as a continual and if necessary incremental state of perpetual evolution, closely linked to prevailing organisational culture. In contrast, Collins [50] offers an alternative perspective, grounded in the belief that empowerment is in fact best understood as emotional development, and as such attempts to "force" empowerment into organisations in the pursuit of espoused benefits without truly appreciating that implications are likely to have adverse consequences will in fact result in "disempowerment" [1]. Collins [50] concludes that if organisations are to derive genuine benefit from the integration of empowerment within organisational culture, they must acknowledge the existence of recognised best practice and human psychology within this field, given that humans are complex and these concepts are inextricably intertwined.
Expanding upon the concept of organisational development and benefits as a direct consequence of introducing empowerment principles, Beach [30] observes that when an organisation creates the necessary conditions for empowerment, through a hybrid combination of classical theory ("best practice") and non-traditional approaches concerned with incremental transactions of trust, direct benefits will ensue. Beach [30] concurs that these may not be de facto quantifiable, but are instead represented by a subtle-or in some cases dramatic - level of improvement in apparently unconnected areas, such as increased engagement as a consequence of inspired learning, and development translated in the form of transferable skills. According to Logan [17] there does not need to be a direct correlation from one discrete action to another, given that true empowerment is an intrinsic process grounded in the belief in inherent trust between employees and their line managers.

More recently, and in light of prevailing economic circumstances in the global business markets and the need to encourage employees to engage and become more effective and efficient, Manyard et al. [59] have critically reviewed the literature pertaining to empowerment in the field of business and management and have determined that there is a division between the practicalities of empowerment and the emotional and psychological nature of its existence in a pragmatic context. In short, they hold that where there is a failure to align the structural and procedural requirements necessary for the conditions of empowerment to exist, then the defining existence of the psychological element cannot be present. Harley [17] is more direct in his approach when he states that:

...the primary source of resistance [to empowerment] is upper-level managers who seem unwilling to confront the disparity between the empowering values they espouse and the disempowering behaviours they model.

In simple terms it can be suggested that in a business context "actions speak louder than words", and unless senior executives are prepared to create a culture and environment of trust necessary to form the foundation of empowerment, it will never be possible to 
engage effectively with employees in this respect.

Within the general focus of research on empowerment, there is consensus that, regardless of the specific context, the notion of empowerment pertains to a situation or culture whereby employees at all levels of the organisation are trusted to work effectively and efficiently within their area of expertise $[21,65,101,59]$. However, beneath this level of agreement, there is an acknowledgement that a combination of intrinsic and extrinsic factors can, and does, directly influence the application of empowerment within a general context. These factors have been observed as including cultural dimensions [29,101,60,102]; gender considerations $[103,66]$ and management styles $[2,3,28]$. A more recent line of reasoning is that considerations of structural empowerment and psychological empowerment also contribute to the discussion [69]. The result is that there is not, and in fact there cannot be, a universally applicable and wholly comprehensive definition of what empowerment may or may not be given the varying strength and impact of variables and extrinsic factors unique to organisational circumstance.

Despite these challenges it is fair to suggest that the principal application of empowerment is typically explored in an organisational context. Thus it focuses on how the function of empowerment directly translates to improved organisational performance. It is only in more recent years that empowerment has been expanded to consider social and societal aspects tempered by geographic location and deep-rooted national beliefs $[27,60,79, \quad 102]$.The implications of this are significant as the world moves forward into an increasingly globalised work environment where multicultural teams are the norm. Furthermore it is necessary to appreciate that, as multinational organisations seek to expand their operations, there is a need to respect the fact that empowerment as a concept is not necessarily interpreted equally by all individuals on a global or indeed localised basis.

\section{Empowerment in the Middle East}

Traditionally, literature-with respect to empowerment within a business and managerial context-has focussed exclusively on Western organisations and culturally understood models of best practice. It is only more recently that scholars have begun to explore the meaning and interpretation of empowerment from a Middle Eastern perspective with a view to appreciating the nuances of empowerment in a culture which is widely perceived by Western scholars as being strongly patriarchal and embedded in a hierarchical society whereby empowerment is not widely encouraged [27,102]. Research into this phenomenon leads scholars to the conclusion that the primary disincentives to empowerment are wholly cultural and grounded in the "beliefs and attitudes, and the skills and knowledge manifested in agency and leading to achievements" [102]. Indeed, it is noted by Sharpia et al. [60] that, especially in the Middle East, empowerment and by implication a form of equality - is more subtle in its context. Sharpia et al. [60] note, for example, that in a Middle Eastern context a more significant emphasis is placed upon relationships which are social in nature as opposed to necessarily granted by right of organisational hierarchy [82]. The implications of this for theoretical research are that the rote application of Western models and concepts of empowerment is likely to over-ride the subtleties of concepts of empowerment as they exist in the Middle East. Manyard et al. [59] suggest that it is important to acknowledge the distinction between the theoretical and the social when discussing empowerment, as humans do not always behave in a rational or logical manner.

It is suggested that in recent years there has been a significant improvement in female engagement in the labour force within the Middle East [104] with increased levels of economic participation [105] greater social voice [106], and increased legal recognition [40]. Cumulatively, these factors can be regarded as "empowerment" insofar as females have obtained increased levels of recognition, power and status in their daily lives. However, empirical evidence in this area also reveals that, in comparison with other socially advanced nations, females in the Middle East comprise a relatively small proportion of the economic workforce [39]. For example, research by the International Labour Organisation [105,107] reveals that only $33.5 \%$ of females in Bahrain are recognised as being economically active, giving Bahrain a global rank of 143 out of 
156 on the female employment index. This raises a series of interesting questions as to why in a wealthy and prosperous region such as the Arab Gulf such a high proportion of the available labour force is deemed to be economically inactive. It is acknowledged that many women contribute indirectly to the economy by ensuring that other members of the household are able to leave the home to work [108], however it is also noted that in other developed economies not only do women fulfil this role of indirect contribution to the economy, they also participate directly, matching their male counterparts like-forlike in terms of employment and status within the organisations for which they work [5].

Recent events in the Middle East (which can be captured in the term, the 'Arab Spring') have thrown a spotlight on the role of female leaders in society and the extent to which they are empowered by their new situation. The Arab Spring is said to have commenced in December 2010 as the culmination of growing civil resentment in several countries in the Middle East. There have been rising numbers of protests and civil action against what is perceived as a dictatorial leadership style in many countries including inter alia Tunisia, Jordan, Egypt, Iraq, and Kuwait [109]. It is suggested that a number of factors has contributed towards the situation, including civil rights abuses, perceived government corruption, and increasing dissatisfaction with the absolute monarchy of some of these nations [109]. It is also noted that over the last decade several Middle Eastern nations have pursued an economic policy of increasing national levels of literacy and education in order to boost economic output and to capitalise upon internal intellectual capital [110]. The unintended outcome of this is a highly educated younger generation many of whom have studied in the West and who have brought back with them cultural ideals associated with democracy [106]. Coupled with this is the rise of technology and increased use of the Internet amongst the population, which has facilitated an exchange of democratic ideas on a scale never before witnessed in the Middle East. Whilst some people have embraced this demographic shift, it also represents a direct challenge to established cultural and social norms which have withstood many generations [111]. It has brought into sharp relief the juxtaposition of empowerment and socio-cultural norms. This creates an interesting challenge for many organisations in the Middle East, in particular those which on one hand wish to embrace what is globally regarded as best practice for employee management, and on the other hand see is a direct challenge and perhaps even threat to established social hierarchy and organisational bureaucracy in many cases [111]. It is noted by Whiteside et al. [102] that it is already difficult to embrace female empowerment in well-established democracies as there have been many years of legislation which encourage equality; given that no such legislation exists in the Middle East, this makes for a particularly interesting area of study.

\section{Women and Empowerment in the Middle East}

As previously discussed, the concept of empowerment as a general term, and also as a specific term when it focuses on female empowerment, is wide-ranging and addresses factors such as employee engagement, individual quality of life and the extent to which there is a degree of perceived equality and fairness in society. Suffice to say the concept of equality leading to female empowerment is also individualistic in its interpretation since it holds different connotations for different people. There is a paucity of detailed research in regard to the leadership roles of female leaders in the Middle East region; however, there have been several recent studies which have assessed the role of female participation in the workplace [110]. Interestingly, these studies reveal a number of similarities between females in the UK workforce and females in the Middle East, although it is acknowledged that cultural diversity has a greater impact on what are considered standard and nonstandard roles of women within an employment capacity.

Having set out the context of empowerment and its varied interpretations and applications, it is finally possible to explore the relationship between women and empowerment, and specifically the nature of that relationship within the context of the Middle East. Quite clearly this is not a straightforward area to explore, given the deep-rooted cultural preferences and social mores that hinder what might be regarded as an unseemly discussion. Accordingly, it must be noted at the beginning that, when 
capturing the opinions and perspectives of female empowerment in the Middle East and within leadership roles, the women in question have already received considerable familial support such as help at home in order to support their career pursuits [60]. In their research into female entrepreneurship as a form of personalised empowerment, In others Research determine that, surprisingly, there is in fact relatively little difference between male and female drivers of empowerment as both genders principally seek self-empowerment in the form of entrepreneurial venture in order to have control over their own destiny and work-life balance and conclude that only a relatively small proportion of females felt that gender dominance or "male push" was the core driver of their wish for empowerment, which contradicts the widely held belief that females are held back in the workplace by the existence of a "glass ceiling".

\section{Leadership and Empowerment}

It is noteworthy that there has been relatively little advancement in this area of research for several years. Comparisons of literature and studies from the 1980s and 1990 s to the present day reveal that the fundamental principles of empowered leadership are widely understood, but the empirical evidence demonstrates that whilst they may be widely understood, they are not widely practised $[112,113,64]$. This distinction is interesting as it presents a new avenue of research in order to understand the causes for the dichotomy between theory and practice. Empowerment, which has been previously discussed as a concept in this study, is clearly acknowledged as a route to enlightened leadership and successful organisations, and thus the logical conclusion ought to be that organisations that wish to do well would be prudent to adopt empowered leadership approaches and styles. However, as the preceding evidence notes, this does not seem to be the case and many organisations appear to perform sub-optimally because of their prevailing leadership style and organisational culture [114,115].

\section{Female Leadership Traits and Empowerment}

The unassailable fact remains that females are grossly under-represented at a senior managerial or leadership level in any cultural setting. A multitude of reasons appear to contribute to this and given past history it is doubtful that the next generation will see any significant change as it will take time for cultural shifts to present themselves in fact. However in spite of this it is still a valuable exercise to attempt to understand whether there are significant differences in female leadership styles and traits, and if so, what impact this has. The rationale for this is that presenting empirical data and facts which conclusively indicate that alternative leadership styles are as successful, if not more successful (assuming that females do have different styles), may help to sway the balance of prevailing opinion and motivate a change towards increased female empowerment.

Extensive research by Goby and Erogul [88] suggests that female leaders possess three main traits which are not as widely evidenced in male leaders. These are summarised as follows: first, women leaders have been found to have greater powers of persuasion than their male equivalents. They are accepting of the fact that there may be more than one way to accomplish a task or goal and so they are more open to negotiation. Secondly, female leaders are better equipped to cope with rejection and failure, which they demonstrate by a renewed attempt at the task in a different manner, illustrating that they have learnt from their mistakes. This is attributed to the fact that female leaders have had to work considerably harder and overcome more hurdles to reach a senior leadership position, and so they are prepared to listen at least to wider advice. Goby and Erogul [88] notes here that male leaders are extremely reluctant to admit errors and would rather repeat the process because they are convinced they are right, rather than accept that some form of adaptation may be necessary. The third point of difference between male and female leaders is found in the fact that women are generally more inclusive and participative in their style. They prefer to work collaboratively and collectively, incorporating the power of teamwork which has acknowledged in organisational literature as an extremely effective means of achieving organisational goals [116].

This has been expressed more directly Other Researcher who suggests that women do not "chase glory" and prestige in leadership 
positions. They are happy to share the credit and the burden with others. As a result of this two factors occur. The first is that because women are not seeking individual acclaim, they are more focussed on the tasks at hand and the overall benefit as opposed to personal glory and recognition. This has obvious benefits for the organisation as a whole. Secondly, women are less focussed on proving themselves as an extension of the organisation and therefore the risks that they do take, for example moving into a new market, are carefully calculated and assessed, and not impulsive or instinctive. The result of this tends to be a much steadier approach to organisational growth and direction which can be justified and understood, and, according to Goby and Erogul [88] this helps to empower the organisation because employees can understand the direction of the organisation and how they fit into it.

The Centre for Women's Business Research presents a fascinating set of statistics which examines the extent of growth in female managed businesses and the level of business failure. They have determined that on global scale female managed businesses have experienced a level of growth which on average has outstripped that of malemanaged businesses in the period 1998-2006. Their research also demonstrated that the growth in female managed businesses was steady and consistent, unlike the growth in male dominated businesses which was far more volatile. The research study suggests that this comparison is akin to the parable of the tortoise and the hare, whereby the steady and measured approaches to business growth facilitated by careful planning and open communication is far more effective in the longer term. They directly attribute this to the predominant leadership style and traits found in female leaders, who review risk and growth more carefully. Perhaps even more interestingly, statistics from the National Statistics Hub and the national credit agency Equifax (2009) reveal that failure rates for women-owned businesses are significantly lower than those of male-owned and managed businesses. The conclusion of Fairlie and Robb [117] is that the predominance of empowered and participative leadership styles amongst women leads to far more effective organisations which are more closely attuned with the needs of organisational stakeholders (both internal and external). Ultimately from this limited review it would seem that the empirical evidence supports the suggestions of Goby and Erogul [88]. In simple terms, whilst culturally it may be unpalatable in certain quarters, the statistical evidence would indicate that women-owned businesses are more stable and successful, and given that this is evidenced in organisations of all sizes and industry sectors the only logical linking factor is leadership style.

\section{Theories of Discrimination/Barriers}

The concept of career implies a series of job assignments that enable a person to move progressively through a series of jobs that provide the necessary background of knowledge and experience that enable an employee to reach a high status position. This is typically what happens with men who begin their careers at entry-level jobs and move up the hierarchy over a period of years. In doing so, they have the advantage of the preferential treatment of males in the workforce that society affords. This not the typical experience of women. They are usually viewed as less qualified than men who might be on a similar career path. Whereas a man might move up the corporate ladder by occupying a series of line management positions that would eventually qualify him for a senior management position, a woman would more likely begin her career with a series of staff assignments. As such, these staff positions delay her progress and, if she takes time off for childrearing, result in a serious delay in her ascension to higher level positions. We have an illustration of why there are so few women in senior management positions, women do not begin their career path in managerial positions like men do; the starting point is already compromised. The case may convey that the pervasiveness of discriminatory behaviors at work encourage women to start up their own business and become entrepreneurs.

The notion of a pipeline barrier has been identified by the Federal Glass Ceiling Commission [118], and it clarified that women's slower progress in their careers was due to the resistance to training, mentoring and education for women in organizations for future promotions. Although the notion of a pipeline has some utility, it often works to the disadvantage of women due to the 
existence of other factors such as the glass ceiling. The challenge for women is to get into the pipeline as soon as possible. Alternatively, they will need to find another avenue for entry into the system where they can have access to advancement opportunities.

\section{Is the Glass Ceiling Real?}

The concept of the "glass ceiling" was formally identified as far back as 1995 . Described by the Federal Glass Ceiling Commission (FGCC), it is the:

...unseen, yet unbreachable barrier that keeps minorities and women from rising to the upper rungs of the corporate ladder, regardless of their qualifications or achievements [118].

The research of has been applied as the benchmark for the existence of the glass ceiling since its publication. Although in academic terms this research can be regarded as old, the wider contextual situation suggests that in fact researchers have only touched the tip of this situation. To offer a simple example, the UK has had equality legislation since the $1960 \mathrm{~s}$, beginning with the Equal Pay Act 1970 and most recently the Equality Act 2010. Throughout this 40 year period there have been numerous attempts to strengthen the legislation because of the persistent gap between the ideology of the legislation and the reality of gender inequality. Suffice to say at the time of writing females are still significantly disadvantaged in the workplace with a landmark ruling in November 2012 finally allowing females to claim backdated pay and compensation for many years of unequal treatment.

The point to take from this is that females at all points of the employment spectrum have been subject to significant examples of direct and indirect in equal treatment [119]. Arguably, direct and tangible examples of inequality are found when pay rates and job benefits are found to be less than those of male contemporaries in the workplace. To a degree this can be readily tackled with legislation although the 40 year gap between legislation and reality suggests that it is a slow process [120]. Bearing in mind that there was a 25 year gap between the initial introduction of equality legislation and acknowledgement of the situation by prevailing government bodies and quangos. They are addressing a long-ignored and socially uncomfortable fact that, even with the existence of legislation, women and minority groups are significantly disadvantaged in positions of seniority across society. The glass ceiling is a gender-specific phenomenon. Although other minority groups face challenges in the workplace, they are not the same as the glass ceiling, which is deemed to apply exclusively to women.

According to Baker and Leightle [121] the glass ceiling prevents a significant proportion of well-qualified female employees from securing prestigious and high-profile positions within organisations. They also assert that women who perceive that they are subject to the glass ceiling are unable to secure the highest paying jobs within the overall organisation or indeed the wider workforce. Arulampalam et al. [122] build on this line of reasoning and suggest that the existence of these invisible barriers can make women feel as if they are in some way incapable of undertaking these roles and Many females in the workforce feel as if they are not "taken seriously", and that their male counterparts and line managers do not consider them as potential candidates for senior and executive roles. This creates a self-fulfilling prophecy whereby females gradually have their confidence eroded and thus cease striving for senior executive positions because they feel that there is no point in so doing. This creates a negative self-image, meaning that females are inherently disadvantaged unless they are able to overcome these perceived barriers.

Although equality legislation in developed nations specifically forbids gender specific discrimination, the statistics as regards females in the boardroom speak for themselves. Very recent research published in the Guardian [123] finds that, despite concerted efforts, fewer than $20 \%$ of organisations had an equal quota of females in the boardroom, and more worryingly the larger and more well-established the organisation the smaller the proportion became. Typically in the UK the glass ceiling seems to hold female representation in the boardroom to an average of $16 \%$ (Peacock, $2012 b$ ). Given that the legislation previously referred to expressly prohibits discrimination on the basis of gender it seems amazing that such a large gap remains between male and 
female representation in senior roles. However, no matter how much it is decried, it is apparent that the situation with regard to the glass ceiling is very real.

The ncertainly in the West there is longstanding legislation which forbids the precise type of discrimination that the glass ceiling represents. Cotter et al. (2001) point out that in spite of the existence of this legislation the glass ceiling certainly does exist, as evidenced by the statistical disparity and female representation in the boardroom and amongst specific gender-divided roles. This is proof positive of the existence of the glass ceiling. They go on to explain that organisations seek to retrospectively selfjustify their disparity in the boardroom by attributing subjective judgements to characteristics and traits of an individual female applying for a senior role. Popular examples of this include confident women who are described in derogatory terms when in the workplace. When a woman is confident in her work, she is often described as aggressive, whereas a male in precisely the same situation would be described as assertive [124]. The former has very negative connotations and the latter positive connotations, with the distinction being so subtle as to be disguised, and a female being made to feel as if she is "over-sensitive" if she challenges this. It would take a supremely confident but not arrogant woman to overcome these barriers which are invisible and intangible and indeed ignored by the vast proportion of the workforce.

According to FGCC [118] there are both technical and psychological factors which contribute to the existence of the glass ceiling, in much the same way that there have been found to be tangible and intangible factors which contribute towards empowerment. It is suggested by the FGCC [118] that the tangible factors related to the refusal of people in the workplace to discuss the existence of the glass ceiling, were evidenced by declining to gather data which would illustrate its existence and thus challenge the root causes. The intangible factors as discussed previously relate to the fact that many females have their selfconfidence and self-belief systematically eroded by organisational and societal norms which directly challenge their belief that they are capable of carrying out the role.
Insch et al. [125] point out that several factors contribute to the sustained existence of the glass ceiling, ultimately leading to the glass cliff discussed by Haslam and Ryan [120]. The first is that organisations have the opportunity to refuse to employ women in senior roles provided that they can justify their decision-making process. The result is that at a senior level it is quite easy for a board to suggest that someone lacks the necessary experience or skill to be appointed to the role [126]. This is permissible under the legislation and prima facie justifiable as a direct result of a self-fulfilling prophecy. To expand, there is a very small proportion of the population with the requisite skill set and experience necessary to lead a large multinational organisation at board level; furthermore, the experience can of course only be gained through tenure in the role. If there are only a very small proportion of women with this experience, this dramatically reduces the available employment pool. Ergo, organisations are then justified in refusing the positions to women on the basis of lack of experience [119]. In order to break this cycle it would be necessary for organisations to take a risk by employing a female at a senior level and for whatever reason it would seem that organisations are extremely reluctant to take this risk.

The second consideration is that there is either a refusal to acknowledge or a refusal to discuss the existence of this barrier, despite the overwhelming statistical evidence. It would seem that organisations can and do retrospectively self-justify their decisionmaking and refusal to employ women in senior roles on the basis of the lack of experience because they cannot be compelled to take the risk and employ women at a senior level [62,127]. The proposed introduction of quotas would of course challenge this situation [123], however this attracts its own challenges, as will be discussed subsequently in section 2.6 below. Thus it would seem that some progress has been made with a willingness at least to discuss the potential merits of quotas even if people do not necessarily agree with them. However, it is suggested by Conley $[4,5]$ that this is still side-stepping the main societal issue which people seem scared to discuss for fear of being perceived as politically incorrect. 
According to both Healy et al. [128] and Cook and Dar [20, 29] the nub of the matter is this: there is a clear and at least partially quantifiable gap between the ideal situation of equality in the boardroom and the reality of the current gender division. Until people are prepared to discuss and acknowledge openly the underlying and deep-seated sociological reasons for this gap, collectively this gap will continue to self-perpetuate. To express this bluntly, it would seem that a significant proportion of men continue to believe that women are unfit for the boardroom. This unpalatable truth is reflected in the statistical evidence, and until this is expressed and openly discussed and the root causes of this belief examined and overturned it is suggested that the glass ceiling will continue to exist.

Ridgeway [129] reveals that for many women there is a complex internal hurdle that they need to overcome in order to reach the petulance of organisations. Expressed concisely, Ridgeway [129] found that a large number of women lacked sufficient selfconfidence to compete directly with men for senior roles in organisations. This is despite the existence of "fast-track" schemes to help women progress and prepare for senior executive positions. Ridgeway [129] attributes this to the fact that women are often less enamoured of the male desire to compete and would rather work collaboratively with colleagues to produce a more effective outcome. Linking this back to the preceding discussions where it has been shown that because it is mostly men who make the decisions about corporate appointments, they perceive that women lack the necessary traits for leadership, such as aggression, directness and decisiveness. In fact Ridgeway [129] believes that women do not lack these skills but rather that they prefer to adopt a collaborative approach, as opposed to a competitive stance. Statistical evidence and research would appear to support the research of Ridgeway [129]. Indeed, there is a considerable and consistent body of research which demonstrates that in the long-term female-run organisations have proved to be more profitable and stable $[117,130,131,132]$. This research is crossnational and would suggest that because females are typically more collaborative in their approach and more risk-averse they take the slow and steady route to sustainable business growth. However, because of this their businesses tend to remain smaller because they do not want to take significant risk and in consequence they retain a low profile.

The implications of this within the context of this research are that females are more than capable of running businesses but because they do so in any different way than men it is considered to be a less successful approach [133]. Despite the evidence which shows that female-run businesses, which by extension have women in senior positions, are in fact more successful albeit on a smaller scale, men working for much larger organisations are able to dismiss these achievements because the skill set required for running a successful but small business is not identical to the skill set required for running a large multinational. It is suggested that this misalignment of perception of skill set is a significant contributor to the limited number of women in senior positions in large organisations. Moreover, expanding on this theme of perceived skill sets, Ridgeway [129] notes that when females who do not have a tendency towards aggression and self-belief were repeatedly told that they were unfit for senior positions because they lacked experience they felt unable to challenge this assertion. Again it is suggested that this links back to the differing perceptions of male and female skill sets with regards to running and managing any size of business. Ultimately because it would seem that men in senior positions within large organisations are unwilling or unable to consider that alternative skill sets may bring value to the corporation, this prevents women from being appointed to senior roles.

\section{The Golden Halo Effect}

Arguably it is the unspoken aspects such as these which contribute to the existence of the glass ceiling. It is a way of circumnavigating the existence of legislation without any form of malicious intent. To express this in another way, it is not necessarily suggested that men deliberately set out to exclude women from senior roles. Rather it is the case that because of their social and corporate interactions which have become selfregulating and self-reinforcing men appear to be unaware of their own deep-rooted prejudices. This manifests itself as the "Golden halo effect". Baltes and Parker [134] along with many other scholars, claim that the Golden halo effect is in fact present in 
many aspects of organisational behaviour, and refers to the cognitive bias which people display when they express a preference for the familiar. In the context of recruitment and selection there is a considerable amount of research which illustrates that this cognitive bias present itself on a very regular basis. The practical implications of this are that those people within the organisation who are responsible for recruitment have a strong tendency only to recruit other people who share similar personality traits. According to a considerable number of research studies, the self-justification for this is that the new employee will be a cultural fit for the organization. Prima facie, this is entirely justifiable as it is very uncomfortable for any employee who does not fit within organisational norms [135]. The problem is that in the long term this self-perpetuation of the golden halo creates a highly introverted organisation which is unable to look outside its own norms and to accept that deviation and variation are, within reason, a positive way of expanding the organisation's skill set and perspective.

Potentially, this line of research may present at least a partial explanation for the continuing situation whereby women appear to be deliberately excluded from the upper excellence of the workplace. Indeed it may also help to explain the glass cliff discussed by Haslam and Ryan [120]. This is because if those in a position of recruiting others to senior executive positions are convinced of their own abilities and unaware of their internal cognitive bias, it is therefore entirely possible that they do not necessarily consider that they have done anything wrong or inappropriate. In fact, an insightful study published by Palmer et al. [136] illustrated this effect. The research of Palmer et al. [136] was action-based and required participants to note their own observations and feelings in a journal within the context of recruitment and selection. This was then statistically analysed by an objective third party. In brief, the results clearly demonstrated that the vast majority of research participants were wholly unaware of their latent cognitive bias and in some cases became quite aggressive when confronted with the evidence, as they denied any wrongdoing. This thorny subject may well present a significant measure of understanding as to how and why the continuing situation whereby women are unable to reach the upper echelons of the workplace is perpetuated.

A similar study conducted by O'Neal [137] also supports the research of Palmer et al. [136], although O'Neal [137] chose to focus specifically on perceptions of appraisal as opposed to recruitment. This has significant implications in the longer term because, if the study of Palmer et al. [136] demonstrates a clear cognitive bias in the recruitment and selection process, even presuming that the potential female candidate is able to overcome the first hurdle, they must then overcome the ongoing challenge of meeting the expectations of the performance appraisal. According to O'Neal [137] who also demonstrates significant evidence of cognitive bias, this is a significant issue for many females. The phenomenon which O'Neal [137] describes is that a line manager has a significant level of expectation of performance as a result of having selected someone who they feel is in effect "in their own image", at the very least in terms of personality. If someone has been recruited on this basis and then fails to perform any expected manner, O'Neal [137] found that a gap in perception developed which caused the line manager to mark down appraisal scores significantly.

O'Neal [137] also found tentative evidence to suggest that the more senior the relationship, that is to say at executive level as opposed to a mid-level or lower level line manager relationship within the organisation, the expectations were greater and divergence from the expectations resulted in an exponential increase in marking down a negative perception. O'Neal [137] did emphasise that further research was necessary in this area although, in light of the other studies and phenomena discussed, it would seem perfectly reasonable that when a great deal of expectation has been placed in the appointment of a senior employee and then they perform in a manner other than is expected, latent cognitive bias in the form of the Gizelis, [138] en halo effect is extremely likely to exert an overall negative perception. Furthermore, there is a line of support for this explanation in the early work of Peeters [139] who established what he called a "positive-negative cognition effect". He demonstrated the exponential relationship between positive and negative expectations of 
employee performance under the umbrella concept of the halo effect. In summary, Peeters [139] noted that when there were high expectations of performance based on cognitive bias and these performance expectations were not reached there was a disproportionately high negative response. However, Peeters [139] also found that this was not an equal and opposite reaction insofar as when there were low expectations of a candidate and they performed better than expected, this did not produce a correspondingly disproportionate positive response. It could be suggested that this early work provides some foundation for the subsequent studies of Haslam and Ryan [120] who coined the term "glass cliff" to describe the situation where people are deliberately placed in a position where it is felt that they will not be able to perform in order for their detractors to be proved correct in that that individual was unsuitable for the task, even though the task was impossible.

\section{The Glass Cliff}

Since The glass cliff concept came as an extension to the glass ceiling by Ryan and Haslam [140,141,142,143] The idea of glass ceiling, the idea-was originally discussed in the mid-1990s as an intangible barrier to minority groups seeking to progress in a corporate capacity. There is some debate around the initial discussions of the glass ceiling and whether or not the concept applies only to women or to minority groups for example ethnic minorities in a specific contextual setting. By the mid-2000's the idea of the glass ceiling was widely accepted and some nations and indeed organisations were taking steps to eradicate the glass ceiling. As an extension of this Ryan and Haslam [140,141] considered the particular situation of women who had succeeded and achieved a senior executive position, however it was noted that in a disproportionate number of cases is winning appeared to "fail". Ryan and Haslam [140,141] identified what they termed the "glass cliff where they believed that women who manage to succeed found themselves the victims of their own success because of the challenges that they faced in their new roles. Although there are growing calls with some arguing that much needs to be understood about the glass ceiling phenomenon, yet, as the barriers appear to be have increasing despite much touting by researchers who claim to have succeeded in overcoming the barriers.

When examining why organisations would willingly choose to effectively create a deliberate failure for a new or newly promoted employee, the motives appear to be particularly complex. In part it is suggested by Ryan et al. [144] that a form of golden halo effect or cognitive bias presents itself. They studied the experiences of female political candidates who were pushed by their respective political parties to run for difficult government constituencies. In conducting a statistical study Ryan et al. [144] found a highly disproportionate number of female candidates were guided by their respective parties into difficult situations. Ryan et al. [144] suggested that the possible reasons for this included the fact that generally the population is more tolerant of failure by females because the perceived standards and expectations are not as high. Therefore, if a female was elected to difficult political seat and was consequently unable to carry out their role to a standard which would have been desired, it was then psychologically and socially acceptable for their performance to be dismissed under the social catch-all of "well, she's only a woman". In essence, the research of Ryan et al. [144] found that a disproportionate number of females in highprofile political candidacies were being set up to fail. Moreover, and perhaps more worryingly, these females were potentially denied the necessary support to help them succeed in a difficult position and avoid the glass cliff. Ryan et al. [144] also found that generally speaking, the population as a whole feels more relaxed towards female political candidates, which means that placing a female in a highly marginal seat helps to win over the electorate. If this can be considered accurate across the entire political spectrum it can be concluded that it is in fact little more than a cynical marketing ploy with the females the unwitting scapegoat.

The research of Haslam and Ryan ([120] and finds that once again a disproportionate number of females in senior positions are in a precarious position whereby they are tasked with completing work which is particularly 
difficult either because of external circumstances or a prevailing organisational culture which has caused a business to slide into a loss-making position. The result on the surface is that it self-perpetuates the belief that women are not capable of performing senior management roles; however because of the nature of the legislation in the UK and other developed nations whereby it would not be legal to state such an opinion explicitly, this is now subjugated and dressed up as female failure. The situation is exacerbated because the number of females in high-profile management roles is relatively limited and this also creates a distorted perception of the capability of females to carry out these jobs.

To offer a simple example which underlines the point, recalling that the mean average percentage of females in senior executive roles in the UK is approximately $16 \%$ [145] and given that there are at best 250 to 300 particularly high-profile organisations as benchmarked against the stock market, this means that there are only 40 women in highprofile employment positions across the entire UK. Broadly speaking the economically active female population of the UK is approximately 14.6 million [145]. This means that $0.000027 \%$ of the female population of the UK holds a senior management position with a listed firm. The point of these calculations is to illustrate that if so much as one female in such a highprofile position makes any form of error then it will be exponentially obvious because of the tiny pool of women capable of carrying out senior executive roles in large organisations. These numbers illustrate how and why concepts such as the glass ceiling and the glass cliff are very real, although they are intangible. When the moderating effects of cognitive bias are thrown into the mix, it becomes much easier to understand how male, university-educated senior managers can dismiss the achievements of females in similar positions even though there is no logical justification for their attitude.

A further angle explored by Ryan et al. [62] provides a more comprehensive examination of the work of Healy et al. [128], Cook and Dar [20,29] and Ridgeway [129], who touched upon the moderating effect of female personality traits and perceptions of selfconfidence. Ryan et al. [62] determined that preferred female modes of thinking, which are predominantly collaborative and supportive in nature, served to exacerbate the glass cliff phenomenon. In part this also links to the discussions of Kirton [83] relating to organisational politics and the fact that because females lack a supportive network within the organisation for which they work this also serves to undermine their position. It will be recalled from these discussions that men within these organisations build a social network outside of work which then transfers itself into the working environment. As a direct consequence of the fact that there are so few females in this environment they are unable to build a social support network which is necessary for them to establish themselves within the organisation. Ryan et al. [62] found that there are two reasons for this. First, males within this working environment are not open to the need to build collaborative networks which can be mutually beneficial because they are predominantly competitive and direct in their approach. Secondly, there will forever remain a social stigma in regards to whether or not males and females can form platonic working relationships.

Although this was not examined in greater depth by Ryan et al. [62], has explored the subject and determined that there is a series of double standards relating to this issue. In short he established that it is acceptable for males in the workplace to socialise, but it is considered socially unacceptable for females to socialise in the same way. This was the case even in countries with a high commitment to democracy and equality. The hypocrisy of these double standards was rarely acknowledged or accepted by males, and to some extent was dismissed as females overreacting or even being regarded as hysterical. When this research is viewed within the context of the glass cliff any evidence that females are deliberately manoeuvred into untenable organisational positions, further coupled with the fact that they have no support network (although that is their preferred modus operandi) it becomes quite obvious how and why women struggle to achieve at a senior level within large organisations. Indeed, it can be asserted that with this unpleasant combination of intrinsic and extrinsic factors it is in fact quite amazing that any females are capable of succeeding at a senior level at all. It would imply that the women who do succeed in these situations have been able to adjust 
their ways of working or their perceptions of the working environment such that they are able to think and potentially work with preferred male traits. Whether they express them in a social setting is at this stage unclear.

\section{Criticisms of the Glass Cliff}

Although the glass cliff concept was widely acclaimed after its first publication subsequent reflection has led to a number of criticisms of this concept. Although Ryan and Haslam [33] provide considerable evidence which illustrates that "scaling the glass cliff", as they put it, is decidedly more difficult for females than males, Adams and Ferreira [146] believe that Ryan and Haslam [33] have over-emphasised this challenge. They point out that there are sufficient females at a senior corporate level to illustrate that women can indeed reach the boardroom should they so wish. Ryan and Haslam [33] have certainly highlighted a valid organisational phenomenon, they have failed to address its root causes and thus fail to present suggested solutions to the problem. In essence they have described the situation but not sought to explain it other than to provide further examples of where it exists. There is further research to be conducted in this area in order to complete or extend this area of research. Although there appears to be no evidence which directly challenges the concept of the glass cliff Blau and Kahn (2007) indicates that it can be extended to other minority groups. In this context the term minority is used carefully, as technically women are not of a minority in society, but they become so as they rise up the career ranks. Blau and Kahn [147] confirm this, agreeing that although other minority groups can experience the same situation, the terminology glass cliff has come to be regarded as being exclusively associated with women in the workplace. However, although Ryan and Haslam [33,120] have continued to present evidence which supports their theory it is suggested that this is an area which would potentially benefit from further research.

There are organisational issues that limit the attainment of highest levels of organisational responsibilities. These are organisational qualities that include the existence of quotas and affirmative action. Cases are cited where these imposed solutions have been used with varying degrees of success.
Another institutional effect is the amount of leadership training and mentoring made available. These are resources under an institution's control and the consequences of their commitments are discussed. Another factor under institutional control is empowerment or the lack of it. The literature indicates that it is both up to the individual to acquire and the institution to facilitate. Sexual harassment is a condition that is under the organisation's ability to control by positive actions in its policies and procedures. The literature shows that failure to control sexual harassment has negative consequences to the individual and the organisation. The human resource department plays a key role in addressing the way institutions address women's issues. The HR department is involved in all aspects of management development. How many women reach senior management levels is a function of the institution's top leadership. Lack of mentors and network are discussed as an example how top management can facilitate the identification of mentors and create networks for exchanging information.

\section{Organisational Barriers Level}

Historically, governments have ceded the rights to business entities to organise and operate their activities within a framework of rules and regulations that govern commercial activities. This includes the right to employ, organise and manage employees as the organisation chooses, provided it is lawful and in compliance with approved regulations. These are the principles and context in which women who aspire to responsible positions in manage must deal with. Women have always been underrepresented in managerial positions, describing them as being "less selfconfident,

less emotionally stable, less analytical, less consistent and having poorer leadership abilities than male managers". There are limitations to Okafor, as the determinants they are utilizing to assess such criteria are inherently flawed and demonstrate considerable bias. Using instruments that have been peer-reviewed or previously assessed would add credibility to the study, Due to the presumed assumptions by the male counterparts about women workers such as: The negative stereotypes featuring women managers as prioritizing their family responsibility above their work, and being emotional and sensitive. Hence, the 
organsiationl barriers to women's underrepresented in top positions could come under the dearth of sufficient legal, personal and practical measures.

\section{Lack of Quota /Affirmative Action (Temporary Special Measures)}

Whilst quotas are believed by some to be a satisfactory solution to the problem of a greater balance of women in the workforce, there are some negative aspects to it. It is another form of discrimination that is a double-edged sword. While it may help improve the problem of gender balance in senior management positions and the boardroom, it also promotes tokenism and resentment on the part of some other organisation members [126]. Quotas have been mandatory in some countries for several years with mixed levels of success Haslam et al., [148]. They are recommended in some situations, with apparently limited impact Sealy and Vinnicombe [56]. They are nonexistent in other countries, according to a report by Bilimoria [119]. Whilst they have the potential for eradicating some barriers to female success by forcing organisations to address the issue directly and overtly, there are potential negative consequences that may be worsen employee relations. The advantage is that it does provide a remedy to a serious social issue. The obvious disadvantage is that it can upset and cause resentment from other organisation members who feel that they are also underrepresented and equally deserving of some consideration.

If quotas are to be used, some options to consider are altered types of corporate employment (i.e. the increase in part time and temporary contracts). The possibly result in new barriers to women's representation at boardroom level. The point here is that quotas can operate through policies and statutes on one hand, and management discretion on the other. In either case, the reflexive nature of the anti-discriminatory position needs to be taken into account.

\section{Female Work-life Balance}

This brings the discussion to the thorny matter of females balancing home and work commitments. The fact of the matter remains that in the main it is women who take time out of their career in order to bring up their children. There are myriad reasons for this, a detailed analysis of which falls outside the scope of this particular study, but in brief it can be asserted that, in the UK at least, the costs of full-time childcare are high and, in order to fund childcare, it is typically necessary for both parents to work full-time unless one parent earns significantly above the average wage. In consequence many women conduct a simple cost benefit analysis and realise that it is in fact more costeffective for them to leave work in order to care for their children [67]. This in turn creates a trickle-down effect as women who return to the workplace often assert that they are unsupported and feel that they lack the necessary skills and experience [130]. Limited statistical evidence exists in this area, but of the evidence which has been presented it has been found that for women who return to the workplace after caring for children on a full-time basis many subsequently leave again because they place greater emphasis on their family as opposed to the daily challenges faced in the workplace. Some of these challenges have been discussed previously in the format of office politics [149,138] and the glass cliff [120].

One further factor to discuss under the banner of work-life balance is the unassailable fact that senior executives work under a "long hours" culture in a highpressure environment, and this requires certain personality traits in order to tolerate this situation for any length of time [61]. It is asserted by Eastin and Prakash, [76] that organisational leaders in large businesses share a significant number of character traits including decisiveness, strategic thinking, high levels of confidence, and in some cases arrogance. Indeed, one study by PricewaterhouseCoopers revealed that in a different context a number of senior executives would in fact be regarded as psychopaths because of the personality traits that they display [63]. The reason that they are not is because by societal standards they are successful in generating profit and growing large businesses. The fact of the matter remains that a large number of women has quite clearly decided that this approach to life does not fit with their personal values. The evidence for this will be recalled from the research of Peacock [150].

\section{The Scandinavian Experience}

As previously noted when discussing some of the criticisms of female quotas for boards, it 
is useful to consider briefly the experiences of some of those countries which have enforced mandatory quotas using legislation. Some of the experiences of organisations within Scandinavia, which was one of the first regions to introduce legislative requirements for female quotas. Focusing on Norway, examined the gender distribution of females in senior business and political roles across the country. He explains that Norway and Sweden have some of the highest levels of female participation of any country in the EU, with over $30 \%$ participation in the political arena and in excess of $40 \%$ representation in high profile business roles. Both countries also have female quotas which are enforced using legislation. He goes on to explain that many people have made the natural assumption that female quotas were the precursor of these high levels of participation; however, research has revealed that this is an erroneous assumption "which places the cart before the horse". In fact, it is more accurate to suggest that females in these countries had worked long and hard for many years to establish current rates of participation and, very significantly, the social structures and support networks evidenced within these countries help to facilitate a much higher level of female participation. For example, women have shared parental leave for childbirth and childcare in the early years of a child's life is heavily subsidised by the state. Granted, income tax is particularly high in Scandinavia but arguably it is put to better social use in terms of encouraging the wider utilisation of Gross Domestic Product (GDP) in the form of economic utility. In the longer term it is asserted that it is preferable to utilise the economic contribution and capability of females by ensuring that they are able to balance work and life commitments; ergo creating a societal support network which facilitates this worklife balance has proved to be effective.

However, one particular significant point to note is that, according to Caul [151]; and Squires [152], the current level of female participation has been particularly hard-won, and in part owes much to over a generation's worth of hard work by women in Scandinavia, coupled with the much greater focus on egalitarian principles evident in Scandinavian society. Although quotas have provided something of a retrospective benchmark for female participation there is still a sigificant number of discrepancies and it should not be assumed that quotas have been a panacea. Indeed, Squires (1996) points out that some 15 years ago when these principles were first being discussed, there was a considerable amount of opposition towards the imposition of quotas. There is a high level of female participation in politics there is still a significant amount of underrepresentation in business. At the time of writing, Sealy and Vinnicombe [153] observe that women in Scandinavia are considerably better represented in terms of proportionality but that they have had to fight hard for the concessions that they have won. The imposition of quotas was directly responsible for the current situation in Scandinavia; rather, he believes that underlying cultural norms created a situation whereby such high levels of female participation are possible. They also note that whilst it is easy to quote high-level of female participation in certain industry sectors such as politics, many other areas still have significant underrepresentation and the mean average statistics which are readily bandied about are misleading.

\section{The Female Perception of Leadership}

In line with the studies of Hartnell et al. [154], which consider female personality and leadership traits, generating a cohesive organisational culture which emphasises collaboration would explain why women are actively choosing not to join the boards of large companies. In short, they recognise the psychological games which senior male executives play and they do not want to join the game. It is further suggested that this is in fact an example of female empowerment because they have made the choice (which is de facto empowering), but the challenge for scholars and legislators to recognise is that this choice is not necessarily obvious. Once again this is linked back to the fact that because people refuse to discuss openly factors such as office politics and cognitive bias, it is easier to use more subtle means to avoid their direct effects. Moreover, as Ryan et al. [62] note, most women prefer to avoid direct confrontation, so taking a circuitous route to a position of economic power, perhaps by establishing and building an SME of their own, most females are able to achieve their desired work-life balance without having to play office politics. It is argued that this is an empowerment choice of its own. 


\section{Criticisms of Female Quotas}

Peacock [150] describes female quotas as " $a$ blunt instrument". She goes on to explain that they will address only half of the problem, that is to say, the obvious figurehead representation of females in the boardroom, and will not address the underlying matter of the lack of pipeline of forthcoming talent, and the fact that there are fundamental socio-cultural issues to address. Jackson [150] believes that quotas are dangerously counter-productive because it they continue to fuel the suspicion that females have been selected for senior roles out of charity or because of enforced quotas and, if they fall prey to the glass cliff phenomenon, she believes that this will create a negative downward spiral which will be extremely hard to reverse. In fact, she goes so far as to assert that as aspiring females see more senior colleagues placed in very difficult positions with a lack of support this will in fact stem the likely pipeline, because the up-and-coming talented females will rapidly identify that they are likely to be handed a poisoned chalice. The implication of this is that it will accelerate the attrition of females from large organisations, because the EU and other government bodies are fundamentally failing to address the underlying assumption as regards female expectation. Indeed, Ryan et al. [62] point out that successful senior women are well aware of the existence of the glass ceiling and a glass cliff, and they play the game of office politics with great care and skill. Other researchers, such as Halsam et al [120], also highlight the fact that women choose to leave the workforce, which further reinforces the implication that they are aware of the glass cliff and choose not to fall off it. They make this choice by voluntarily exempting themselves from a position where they may be inadvertently or otherwise pushed into an unsuitable role.

An insightful study by the Interparliamentary Union [155] also found that there is limited statistical evidence which supports the mandatory imposition of quotas or sanctions. Indeed they found that in countries such as Rwanda and Cuba, nations not noted for their commitment to democracy, more than $50 \%$ of their elected parliaments had female representation; in fact in Rwanda $56 \%$ of parliamentary candidates are female. Other nations which already had over $40 \%$ of female representation in senior leadership roles included Sweden (45\%) and the Netherlands (41\%). What was notable was that, despite its apparent levels of democracy, Sweden has the highest levels of recorded sexual discrimination and assault of any EU nation, even making allowances for the fact that they may have a more open reporting system. In comparison, the UK, which is widely regarded as one of the most democratic and tolerant nations, can only boast $16 \%$ female representation at a senior level. Even the United Arab Emirates (UAE), which serves as the comparator for the study, was able to demonstrate $23 \%$ of female representation at a senior level, which makes something of a mockery of the UK's established democracy and representation requirements. The implications are quite clear: if non-democratic nations such as Rwanda and the UAE have higher levels of female representation at a senior level it clearly suggests that the imposition of mandatory quotas and legislative sanctions will have virtually no impact other than to create unnecessary bureaucracy and resentment, and potentially weaken organisational boards. It is also quite evident that the root causes of low female representation at a senior level in the boardroom are societal. It would also seem that the true root causes are likely to present unpalatable truths about society's attitude towards female representation at a senior level.

\section{The Evidence and Arguments for and against Quotas}

Research by Anderson et al. [67] has shown that boards with a high proportion of females and are often closer to representing their client base, meaning that it is easier for the organisation to make strategic decisions about organisational growth, product development and marketing. A further line of support for female membership of executive boards is that in order to appeal to a wider market it is important to have an executive board which reflects the target market, and alternative perspectives. As females are able to offer this, there is logical justification for their inclusion on the board.

Other arguments in favour of quotas suggest that quotas simply serve to rebalance the natural barriers that women face as they seek to climb the career ladder. These have been discussed in depth earlier in this 
chapter but can be summarised as the deeprooted societal belief that women are somehow less capable than men because they are perceived as less confident and capable of leading on a task basis. It is also been suggested in previous discussions that although women can be as, if not more, qualified than their male counterparts from a technical perspective, their capabilities are downgraded or discounted, and because women typically do not seek to self-promote in the same way as men, they serve to reiterate this belief. Finally, as part of the double-edged sword that is the introduction of quotas, there is some evidence from the political arena that the introduction of female quotas helps to increase or improve the democratic process.

The arguments against the introduction of quotas are, however, equally compelling. The first and most obvious relates to the fact that an almost inevitable consequence of the introduction of female quotas is that women who are unfit or unsuitable for a leadership role will be promoted ahead of their capability thus placing the organisation at risk as well as themselves, in terms of their ability to cope with a highly stressful situation.

Arguably, the introduction of quotas will do nothing to reverse this problem and will almost inevitably exacerbate it because of the previously discussed deep-rooted social beliefs and the difficulties of overlaying regulation and legislation upon social preferences when the two are not in accordance. The quotas are undemocratic and in breach of equality legislation because they naturally favour one social group over another. No matter which way this argument is discussed, it could not be considered as democratic or equal, and has implications of subjectivity, given that certain individuals will decide whether or not rules should be applied differently in order to meet the requirements of prima facie contradictory legislation. Quotas have also been challenged as being undemocratic [142], and patronising because many women in senior leadership positions would far rather be assured that they had achieved the position on merit, as opposed to being handed the position on the basis of their gender.

Such women are likely to be challenged by the introduction of quotas as it will undermine the work that they have done in order to achieve their role. Finally, there is the practical consideration that if quotas are introduced then better qualified candidates will be disregarded or eliminated simply for being male and accepting the minimum requirements of quota. As previously noted this is likely to be highly damaging both at an individual level and to an organisation as a whole. Potentially this is also damaging to society in the longer term, because it will inherently weaken the economic survival of businesses if inappropriate candidates are given positions of power which they are not equipped to handle.

In light of these discussions it is suggested that although Scandinavia has had positive experiences of quotas, attempts to introduce forced female quotas for board positions will exacerbate the problem and not resolve it. The reason for this is that the paradox between individual belief and collective belief still undermines the position of women in leadership. Attempting to force societal change through legislation is, at best, a short-term measure, and, at worst, will be extremely damaging at multiple societal, organisational and individual levels, because it undermines the position of women in society and promotes the belief that they must benefit from charity and not be given parity. This will only serve to reiterate the view that women are incapable of leading. This is in spite of the fact that there are many highly successful female entrepreneurs of small businesses and a limited number of high profile females in leadership positions. The paradox remains and history has already proven that legislation does very little to rebalance societal attitudes. For this reason quotas are not recommended unless prevailing societal norms will accommodate and support them.

\section{Concluding Thoughts}

These have comprised a discussion of empowerment itself, its meanings, theories, applications and interpretations. There has also been a detailed discussion on leadership, with specific focus on the role of female leadership and the extent to which females have a different or divergent leadership style and how this is impacted and influenced by organisational and national culture. Amongst the concrete barriers breed The glass ceiling appears to be an impenetrable embodies discriminatory behaviours 
including gender and racial inequality that is faced by women in the workplace and prohibit them from promotion to higher leadership positions in the business at the corporate world. These have comprised a discussion of women's barriers to their progression, its meanings, theories, applications and interpretations. There has also been a detailed discussion on leadership, with specific focus on the role of female leadership and the extent to which females have a different or divergent leadership style and how this is impacted and influenced by organisational and national culture.

The bias at the organsiations deprive qualified women from advancing upward into top management level positions and cause deeply entrenched discrimination within the employees.Therefore, its unhealthy for the organisation and the society overall to split the workforce promotions and the upper positions for only one gender.There has been a considerable discussion within this as regards the concept of the "glass ceiling and the cliff" which describes the phenomenon of women being promoted to leadership roles and then given limited support, resulting in subsequent failure. The final section has discussed the matter of quotas, and the respective benefits and drawbacks of the quotas system in reducing gender discrimination at the boardroom.

The predominant themes which have emerged from this comprehensive literature review can be summarised as follows. Certainly there is plentiful evidence to demonstrate that female leaders are as, if not more, capable than their male counterparts. Reasons for this include their natural leadership style being collaborative and cooperative, leading to an engaged workforce. They are also risk-averse and take a strategic or holistic view in regard to business decisions, leading to a more balanced level of organisational growth. There is some limited evidence to suggest that there are physiological reasons to support this (principally the ability of most women to manage and monitor multiple streams of information simultaneously), which is clearly a desirable trait in a leadership situation. However, the statistical evidence shows that time and again women are either denied leadership positions or choose not to pursue them beyond a particular managerial level. There is debate surrounding this as to whether women choose to opt out or are forced to do so by extrinsic and intrinsic societal pressures. Some research has shown that women who do opt out of senior roles by choice often choose to pursue personal interests and are highly successful.

In light of the fact that it has been proven that women must fight harder than men to achieve a similar position it is not remotely surprising that women choose to empower themselves at a lower societal level and direct their energies towards positive growth, as opposed to political infighting. However, there is strong evidence for the paradox of societal pressure perceiving that women are less capable of filling senior and high profile leadership positions.

This evidence is paradoxical because it only exists in a collective situation under the principles of societal norms, and not as displayed by individuals in a clinical setting. This paradox not only explains the ineffectiveness of existing legislation but also provides the foundation of the argument as to why enforce quotas would in fact be counterproductive. Ultimately it is therefore concluded that whilst some women have been able to demonstrate empowerment in a social setting because of a combination of innate beliefs and societal support, the overriding conclusion of this work is that empowerment requires a specific combination of individual capability and societal support in order that women can achieve positions of empowerment. This is further complicated by the fact that empowerment may mean different things to different people and so it is possible for a woman to perceive that she is empowered at a lower level of the organisation because this is what she would like to achieve. It is clear that there is no single answer to the question of empowerment as it is reliant upon a considerable number of alternative variables, and therefore the framework sketched out below indicates the range of factors which can influence perceptions of empowerment at an individual, organisational and societal level.

Overall, the literature suggests that the juxtaposition of general categories and definitions, i.e. women executives, corporations, culture, empowerment and diversity, are not necessarily helpful in determining either the causes of women's 
relative disadvantage, or the means of addressing them.

Above all, the fact that most empirical studies have been conducted in particular cultural contexts (i.e. Scandinavia in the case of studies in quotas, United States and Europe in terms of the barriers) must be acknowledged as an important consideration. Whilst this variable remains salient across the available evidence (and it is difficult to perceive a viable means of eliminating it), the degree to which women executives' predicament may be visualised holistically must remain questionable. For example, since power and gendered behaviour (i.e. masculinity/femininity) have been identified as key determinants of cultural difference, these variables cannot be assumed to operate similarly across cultural contexts. This, it is argued here, suggests that assumptions about relatively under-scrutinised contexts

\section{References}

1 Cox A, Zagelmeyer S, Marchington M (2006) Embedding employee involvement and participation at work. Human resources Management Journal, 16(3):250-267.

2 Denham-Lincoln N, Travers C, Alimo-Metcalfe 1995s, P, Wilkinson A (2002) The meaning of empowerment: The interdisciplinary etymology of a new management concept. International Journal of Management Reviews, 4(3):271-290.

3 Cooney R (2004) Empowered self-management and the design of work teams. Personnel Review, 33(1):677-692.

4 Conley H (2011a) Flexibility and equality: Friend or foe? In Healy, G., Kirton G. and Noon, M. (eds) Equality, inequalities and diversity-Contemporary challenges and strategies Basingstoke: Palgrave Macmillan p. 19-32.

5 Conley H (2011b) The road to equality: Legislating for change? In Wright, T. and Conley, H. (eds) Gower handbook of discrimination at work Basingstoke: Gower P.1 -11.

6 International Labour Office (2004) Breaking through the glass ceiling: women in management, ILO, Geneva.

7 Goodman JS, Fields DL, Blum TC (2003) Cracks in the glass ceiling in what kind of organisations do women make it to the top? Group Organisation Managament, 28(4):475-501.

8 Peebles D, Darwazeh N, Gosheh HD, Sabbagh DA (2004) "Factors Affecting Women Participation in the Private Sector in the Jordan.” National Center for Human Resource Development. (i.e. Bahrain) cannot be relied upon, and neither can cross-sectional studies (i.e. dated ones) in other areas. Correspondingly, there is a continuing need to update and broaden the available knowledge base.

It is debatable which approach would be better employed in the study of the situation in Bahrain, however, given the lack of prior material, that might have suggested a particular sector as the focus, it was inevitable that a pan-sector approach be adopted in this case. These considerations may be added the issue of cross-cultural management, especially in the considerations of power distance and masculinity and femininity. As indicates, certain types of organisation have the capacity to develop traits that cross national or regional boundaries, and this is something that clearly needs to be factored into the relevant research [156-222].

9 Maithani A, Misra M, Potnis S, Bhuwania S (2012) The Effect of Gender on Perception of Glass Ceiling, Mediated by SRO and Attitude toward Women as Managers Management and Labour Studies, 37:107-123.

10 Jain N, Mukherjee S (2010) The perception of 'glass ceiling' in Indian organizations: An exploratory study. South Asian Journal of Management, 17(1):23-43.

11 Ackers P, Lincoln ND, Travers, Wilkinsom A (2012) The meaning of empowerment: The interdisciplinary etymology of a new management concept. International Journal of Management Reviews, 4(3):271-290.

12 The Committee for Economic Development (CED), Fulfilling the Promise: How Women on Corporate Boards Would Make America and American Companies More Competitive, 2012.

13 Catalyst (2011) The Bottom Line: Corporate Performance and Women's Representation on Boards (2004-2008) www.catalyst.org/file/445/the_bottom_line_corporat e_performance_and_women's_representation_on_bo ards_(2004-2008).pdf]

14 Grant Thornton (2012) Women in Senior Management: Still Not Enough, Grant Thornton International Business Report 2012, Grant Thornton Ltd.

15 Browning V, Edgar F, Gray B, Garrett T (2009) Realising competitive advantage through HRM in New Zealand service industries. The Service Industries Journal, 29(6):741-760. 
16 Stanley G (1994) Organisational culture and individual sense making: A schema-based perspective. Organisation Science 5(3):309-321.

17 Logan L, Harley WB, Pastor J, Wing LS, Glasman N, Hanson L, Collins D, Cleary BA, Miller, J, Hegedahl P (1996) Observations on the state of empowerment in today's organization. Empowerment in Organizations, 4(1):6-11.

18 Wright PM, Dunford BD, Snell, SA (2001) Human resources and the resource based view of the firm. Journal of Management, 27:701-721.

19 Durbin S, Conley H (2010) Gender, labour process theory and intersectionality: Une liason dangereuse? In Thompson $\mathrm{P}$, Smith $\mathrm{C}$ (Eds) Working life. Renewing labour process analysis Basingstoke: Palgrave Macmillan P. 81-97.

20 Dar S (2008) Realizing development: Reports, realities and re-envisioning the self. In Dar, S., and Cooke, B., (eds) The new development management: Critiquing the Dual Modernization City: Publisher, 177-197.

21 Nykodym N, Simonetti JL, Nielsen WR, Welling B, (1994) Employee Empowerment. Empowerment in Organizations, 2(3):45-55.

22 Pastor J (1996) Empowerment: What it is and what it is not. Empowerment in Organizations 4(2):5-7.

23 Healy G (2010) 'Reflections on researching intersectionality and inequality regimes' in Ozbilgin, M., (ed) Theory and Scholarship in Equality and Diversity-A Research Companion, London: Edward Elgar.

24 Healy G, Bradley H, Mukherjee N (2004) 'Inspiring Union Women-Black and minority ethnic women in trade unions in Healy G., Heery E, Neumayer E, De Soysa, (2011) and Brown, W., 'The Future of Worker Representation', London: Palgrave p.103126.

25 King-Duvall C (1999) Developing individual freedom to act: Empowerment in the knowledge organization. Participation and Empowerment: An International Journal, 7(8):204-212.

26 Chamberlin J (1997) A working definition of empowerment. Psychiatric Rehabilitation Journal, 20(4):43-46.

27 Baird K, Wang H (2010) Employee empowerment: Extent of adoption and influential factors. Personnel Review, 39(1):574-599.

28 Bartunek JM, Spreitzer GM (2006) The interdisciplinary career of a popular construct used in management: Empowerment in the late $20^{\text {th }}$ century. Journal of Management Inquiry, 15:255.

29 Cook S (1994) The cultural implications of empowerment Empowerment in Organizations, $2(2): 9-13$.
30 Beach AJ (1996) Empowerment to the people: Creating an atmosphere for growth. Empowerment in Organizations, 4(1):29-33.

31 Lee M, Koh J (2001) Is empowerment really a new concept? International Journal of Human Resource Management, 12(4):684-695.

32 Howard C (1997) High involvement leadership: Moving from talk to action. Empowerment in Organizations 5(4):185-192.

33 Ryan MK, Haslam SA (2004) Beyond the glass ceiling. Women in the boardroom: A bird's eye view. CIPD Change Agenda. June London: CIPD.

34 Thomas KW, Velthouse BA (1990) "Cognitive Elements of Empowerment: An 'Interpretive' Model of Intrinsic Task Motivation". Academy of Management Review, 15(4):666-681.

35 Collins English Dictionary (2011) Definition of Empowerment Oxford Collins.

36 Mayoux L (2000) "Microfinance and the empowerment of women: A review of the key issues". Social Finance Unit Working paper, 23. Geneva: ILO [online] available at Ilo_data/public/english/empoyment/finance/downloa d/wp23.wpd. Retrieved 30th April 2012.

37 Kabeer N (2001) Reflection on the measurement of women's empowerment In Discussing women's empowerment theory and practice Sida studies.No.3.Nvum Grafiska AB: Stockholm.

38 Kabeer N (2005) Gender equality and women's empowerment: A critical analysis of the third millennium development goal. Gender and development, 13 (1):13-24.

39 United Nations (UN) (2009) World Survey on the Role of Women In Development: Women's Control over Economic Resources and Access to Financial Resources, including Microfinance. [online] available at http://www.un.org/womenwatch/daw/public/ World Survey 2009.pdf retrieved 30 ${ }^{\text {th }}$ April 2012

40 Al-Gharaibeh (2011) Women's Empowerment in Bahrain Journal of International Women's Studies, 12(3):96-113.

41 Ghorbani M, Ahmadi S (2011) Relationship Between Employee's Empowerment Dimensions and Creativity Improvement in Educational Organizations Middle-East. Journal of Scientific Research, 10(2):213-217.

42 Badran M (2005) Between secular and Islamic feminisms: reflections on the Middle East and beyond. Journal of Middle East Women's Studies, 1:1: Winter, pp. 6-29.

43 Husein Al-Jawaheri, Yasmin (2008) Women in Iraq: The Gender Impact of International Sanctions I.B. Tauris: London. 
44 Khalil Safari, Abdorahman Salim Haghighi, Ahmad Rastegar, Akbar Jamshidi (2011) The relationship between psychological empowerment and organizational learning Procedia. Social and Behavioral Sciences, 30:1147-1152.

45 Hamid Tohidi, Mohammad Mehdi Jabbari (2012) The aspects of empowerment of human resources Procedia. Social and Behavioral Sciences, 31:829833.

46 Al Najjar (2006) Women's Rights in the Middle East and North Africa: Arabic Translation, Freedom House.

47 Ahmed (2010) Women's Rights in the Middle East and North Africa: BAHRAIN Freedom House.

48 Mason K (1986) The status of women: Conceptual and methodological issues in demographic studies Sociological Forum 1(2):284-300.

49 Mayoux L (2001) Tackling the down side: Social capital, women's empowerment and micro-finance in Cameroon Development and Change, 32:435-464.

50 Collins D (1994) The disempowering logic of empowerment. Empowerment in Organizations, 2(2):14-21.

51 Longva AN (2005) Neither Autocracy nor Democracy: Citizens, Expatriates and the Social Political System in Kuwait, in P. Dresch and J. Piscatori (eds.), Monarchies and Nations: Globalization and Identity in the Arab States of the Gulf. London: IBTauris.

52 Al-Enezi, Awadh Khalaf (2002) Kuwait's employment policy: it's formulation, implications and challenges International Journal of Public Administration, 25(7):885-900.

53 Scholl (2006) Gender Segregated Universities and Classrooms: Necessarily a Bad Thing? [online available at http://h06.cgpublisher.com/proposals/387/index_ht ml retrieved 30th April 2012.

54 Metcalfe BD (2011) Women, empowerment and development in Arab Gulf States: a critical appraisal of governance, culture and national human resource development (HRD) frameworks Human Resource Development International, 14(2):131-148.

55 Gibbon M (2000) The health analysis and action cycle an empowering approach to women's health. Sociological Research Online, 4:1-29.

56 Sealy R, Vinnicombe S (2010) Boardroom balance. Management Focus, (28):24-25.

57 Kumra S, Vinnicombe S 2010) Impressing for success: A gendered analysis of a key social capital accumulation strategy Gender Work and Organization, 17(5):521-546.

58 Pearson CAL, Chatterjee SR, (1996) Implementing empowerment through subunit clusters: A Western
Australian case study. Empowerment in Organizations, 4(3):16-25.

59 Maynard T, Gilson LL, Mathieu ME (2012) Empowerment-Fad or fab? A multilevel review of the past two decades. Research Journal of Management, 38(4):1231-1281.

60 Shapira T, Khalid A, Azaiza F (2010) Arab women principals' empowerment and leadership in Israel. Journal of Educational Administration, 48(6):704715 .

61 Allen A (2009) Rethinking power. Hypatia, 13(1):21-40.

62 Ryan MK, Haslam SA, Hersby MD, Bongiorno R (2011) Think crisis-think female: The glass cliff and contextual variation in the think managerthink male stereotype. Journal of Applied Psychology, 96(1)?:470-484.

63 Gajjala R, Zhang Y, Dako-Gyeke P (2010) Lexicons of Women's Empowerment Online. Feminist Media Studies, 10(1):69-86.

64 Roberts J (1984) The moral character of management practice. Journal of Management Studies 21(3):287-302.

65 Rodrigues CA (1994) Employee participation and empowerment programs: Problems of definition and implementation. Empowerment in Organizations, $2(2): 29-40$

66 Olsson S, Walker R (2004) "Two wo-men and the boys": Patterns of identification and differentiation in senior women executives' representations of career identity. Women In Management Review, 19(5):244-251.

67 Anderson S, Eswaran M (2009) What determines female autonomy? Evidence from Bangladesh. Journal of Development Economics 90:179-191.

68 Anderson BA (2005) Expatriate selection: Good management or good luck? The International Journal of Human Resource Management 16(4):567-583

69 Becker BE, Huselid MA (2006) Strategic human resources management: Where do we go from here? Journal of Management, (December) 899-925.

70 Blackburn RM, Jarman J (2006) Gendered occupations: Exploring the relationship between gender segregation and inequality. International Sociology, 21(2):289-315.

71 Wright PM, Dunford BD, Snell, SA (2001) Human resources and the resource based view of the firm. Journal of Management, 27:701-721.

72 Beale D, Hoel H (2011) Workplace bullying and the employment relationship: Exploring questions of prevention control and context. Work, Employment and Society, 25(1):5-19. 
73 IDS (2011) Racial harassment in the workplace IDS Employment Law Brief. No 937, November 12-19.

74 Miller H, Rayner C (2012) The form and function of "bullying" behaviors in a strong occupational culture bullying in a UK police service. Group Organization Management, 37(3): 347-375.

75 Heimovics RD, Herman RD, Jurkiewicz CL (1995) The political dimension of effective nonprofit executive leadership. Nonprofit Management and Leadership: A Quarterly Journal, 5(3):233-248.

76 Eastin J, Prakash A (2013) Economic Development and Gender Equality: Is there a Gender Kuznets Curve? World Politics, 65(1).

77 Bolman LG, Deal TE (1992) Reframing leadership: The effects of leaders' images of leadership. In Clark, K.E., Clark, M.B, and Campbell, D. (Eds) Impact of leadership Greensboro, NC: Center for Creative Leadership p. 509-534.

78 Ross ML (2009) Does Oil Wealth Hurt Women? A Reply to Caraway, Charrad, Kang, and Norris. Politics and Gender, 5(4):575.

79 Barton H, Barton LC (2011) Trust and psychological empowerment in the Russian work context. Human Resource Management Review, 21(1):201-208.

80 Klasen S, Schüler D (2011) Reforming the genderrelated development index and the gender empowerment measure: Implementing some specific proposals. Feminist Economics, 17(1):1-30.

81 Gaunt R (2012) Breadwinning moms, caregiving dads: Double standards in social judgments of gender norm violators. Journal of Family Issues 0192513X12438686, first published on April 4, 2012 doi:10.1177/0192513X12438686.

82 Abu-Rabia-Queder S, Oplatka I (2008) The power of femininity-Exploring the gender and ethnic experiences of Muslim women who accessed supervisory roles in a Bedouin society. Journal of Educational Administration, 16(3):396-415.

83 Kirton GG (2011) Gender, equality, diversity and a new industrial relations paradigm?' in Townsend, K. and A. Wilkinson (2011) (eds) The Future of Employment Relations: New Paradigms, New Developments Basingstoke: Palgrave Macmillan.

84 Becker BE, Gerhart B (1996) The impact of human resource management on organisational performance: Progress and prospects. Academy of Management Journal, 39(4):779-801.

85 Detert JR, Edmondson AC (2011) Implicit voice theories: Taken-for-granted rules of self-censorship at work. Academy of Management Journal, 54(3):461-488.

86 Saks A (2006) Antecedents and consequences of employee engagement. Journal of Managerial Psychology, 21(7):235-242.
87 Whiteoak Crawford, Mapstone (2006) Impact of Gender and Generational differences in work attitudes and Values in Arab culture. International Business Review, 48(11):77-94.

88 Goby VP, Erogul MS (2011) Female entrepreneurship in the United Arab Emirates: Legislative encouragements and cultural constraints. In Women's Studies International Forum, 34(4):329-334

89 Drake J, Blake J, Swallow B (2009) Employer engagement: The critical role of employee commitment. Education and Training, 51(1):54-65.

90 Ashamalla M (1998) International human resource management practices: The challenge of expatriation. Emerald, 8(2):54-65.

91 Healy G, Kirton G (2002) Professional and Highly Qualified Women in Two Contrasting Trade Unions' in Colgan, F. and S. Ledwith Gender, Diversity and Trade Unions: International Perspectives, Routledge: London.

92 De Vos A, Meganck A (2009) What HR managers do versus what employees value: Exploring both parties' views on retention management from a psychological contract perspective. Personnel Review, 38(1):45-60.

93 Espino-Rodríguez TF, Padron-Robaina V (2006) A review of outsourcing from the resource-based view of the firm. International Journal of Management Reviews, 8(1):49-70.

94 Farrell K (2001) Human resource issues as barriers to staff retention and development in the tourism industry. Irish Journal of Management, 22(2):1-18.

95 Gerhart B (2005) Human resources and business performance: Findings, unanswered questions, and an alternative approach. Management Revue, $16(2): 1-14$

$96 \mathrm{Hu}$ J, Wang Z, Liden, RC, Sun J (2012) The influence of leader core self-evaluation on follower reports of transformational leadership. The Leadership Quarterly, 10(1):1048.

97 High-Pippert A, Comer J (1998) Female Empowerment. Women \& Politics, 19(4):53-66.

98 Bass BM (1990) From transactional to transformational leadership: Learning to share the vision. Organizational Dynamics (Winter), 19-31.

99 Alimo-Metcalfe B (2010) An investigation of female and male constructs of leadership and empowerment. Gender in Management: An International Journal, 25(8):640-648.

100 Pellegrino G, D'Amato S, Weisberg A (2011) 'The gender dividend: Making the business case for investing in women', Deloitte Touche Tohmatsu Prichard, P., (1977) "Organizational, work, and personal factors in employee turnover and absenteeism1, Psychological Bulletin, 80:151-76.

101 Harris PR (2004) European leadership in cultural synergy. European Business Review, 16(4):358-380. 
102 Whiteside M, Tsey K, Earles W, (2011) Locating empowerment in the context of indigenous Australia. Australian Social Work, 64(1):113-129.

103 Okanlawon G (1994) Women as strategic decision makers: A reflection on organizational barriers. Women in Management Review, 9(4):25-32.

104 Healy G, Heery E, Neumayer E, De Soysa 2011,P., (2004) 'Representation at Work: Themes and Issues', in Healy, G., Heery, E., Neumayer, E., \& De Soysa, 2011,P., and Brown, W., 'The Future of Worker Representation London: Palgrave p.1-36.

105 International Labour Organisation (ILO) (2009) Global Employment Trends for Women [online] available at http://www.ilo.org/wcmsp5/groups/public/@dgreport s/@dcomm/documents/publication/wcms_103456.pdf retrieved $30^{\text {th }}$ April 2012.

106 Roald AS (2009) Islamists in Jordan: Promoters of or Obstacles to female Empowerment and Gender Equality?. Religion and Human Rights, 4(1):41-63.

107 ILO (2010) Female Employment Ranking: Bahrain [online] available at http://www.nationmaster.com/graph/lab_fem_eco_a ct-labor-female-economic-activity retrieved $30^{\text {th }}$ April 2012.

108 Healy G, Heery E, Neumayer E, De Soysa (2004) 'Representation at work: Themes and issues', 1-36, in 'The Future of Worker Representation', edited by G. Healy, E. Heery, P. Neumayer, E., \& De Soysa, 2011, W. Brown, London: Palgrave.

109 Economist, The (2012) How to set Syria free in The Economist [February 11, 2012] Retrieved 12th Nov 2012.

110 Al-Suwaihel O (2009) Kuwaiti female leader's perspectives: The influence of culture of their leadership in organisations. $\mathrm{PhD}$ Thesis.

111 Al-Yahya KO (2009) Power-influence in decision making, competence utilization, and organizational culture in public organizations: The Arab world in comparative perspective. Journal of Public Administration Theory 19(2):385-407.

112 March J (2007) The study of organizations and organizing since 1945. Organization Studies, 28(1):9-19.

113 Courpasson D (2006) Managerial strategies of domination: Power in soft bureaucracies. Organization Studies, 21(1) 141-161.

114 Fleming P, Spicer A (2007) Contesting the corporation Cambridge: Cambridge University Press.

115 Fleming P, Spicer A (2003) Working at a cynical distance: Implications for power, subjectivity and resistance. Organization, 10(1):157-180.
116 Kumar KP, Chandrashekara B (2012) The level of women empowerment in urban Karnataka: A spatial analysis. Asian Journal of Development Matters, 6(2):92-98.

117 Fairlie RW, Robb AM (2009) Gender differences in business performance: Evidence from the characteristics of business owners' survey. Small Business Economics, 33(4):375.

118 Federal Glass Ceiling Commission (FGCC) (1995) Solid investments: Making full use of the nation's human capital Washington, D.C.: U.S. Department of Labor, November 4.

119 Bilimoria D (2009) Women on corporate boards of directors: International research and practice Cheltenham: Edward Elgar Publishing.

120 Haslam SA, Ryan MK (2008) The road to the glass cliff: Differences in the perceived suitability of men and women for leadership positions in succeeding and failing organizations. Leadership Quarterly, 19(1):530-546.

121 Baker B, Lightle SS (2001) Cracks in the glass ceiling: An analysis of gender equity in the federal government auditing career field. Journal of Government Financial Management, 50(3):18-26.

122 Arulampalam W, Booth AL, Bryan ML (2006) Is there a glass ceiling over Europe? Exploring the gender pay gap across the wage distribution. Industrial \& Labor Relations Review, 60(2): 163186.

123 Guardian, The (2012) Boardroom equality: Binders full of women [online, $18^{\text {th }}$ Nov 2012] The Guardian Editorial available at http://www.guardian.co.uk/commentisfree/2012/nov/ 18/boardroom-equality-binders-women retrieved 27 th Nov 212

124 Judge TA, Livingston BA (2008) Is the gap more than gender? A longitudinal analysis of gender role orientation, and earnings. Journal of Applied Psychology 93(5): 994-1012.

125 Insch GS, McIntyre N, Napier NK (2008) The expatriate glass ceiling: The second layer of glass. Journal of Business Ethics, 83(1):19-28.

126 Seierstad C, Healy G (2012) Women's equality in the Scandinavian academy: A distant dream. Work, Employment and Society, 26(2):296-313.

127 Kumra S, Vinnicombe S (2008) A study of the promotion to partner process in a professional services firm: How women are disadvantaged. British Journal of Management, 19(S1):65-74.

128 Healy G, Kirton Noon M (2011) 'Inequalities, intersectionality and equality and diversity initiatives: the conundrums and challenges of researching equality, inequality and diversity' in Healy G, Kirton G, Noon M (2011) Equality, Inequalities and Diversity Basingstoke: Palgrave Macmillan.

129 Ridgeway CL (2001) Gender, status, and leadership. Journal of Social Issues, 57(4)/:637-655. 
130 Coleman S (2007) The role of human and financial capital in the profitability and growth of womenowned small firms. Journal of Small Business Management, 45(3):303-319.

131 Bird BJ, Brush CG (2002) A gendered perspective on organizational creation. Entrepreneurship Theory and Practice, 26(3):41-65.

132 Brush CG (1992) Research on women business owners: Past trends, a new perspective and future directions. Entrepreneurship Theory and Practice, 16(4):5-31.

133 Gries T, Naudé WA (2009) Entrepreneurship and regional economic growth: Towards a general theory of start-ups. The European Journal of Social Science Research, 22(3):309-328.

134 Baltes BB, Parker CP (2000) Reducing the effects of performance expectations on behavioral ratings. Organizational Behavior and Human Decision Processes, 82(2):237-267.

135 Intons-Peterson MJ, Samuels AK (1998) The cultural halo effect: Black and white women rate black and white men. Bulletin of the Psychonomic Society, 11(5):309-312.

136 Palmer J, Thomas, A, Maurer T (2003) Moderating effects of context on the relationship between behavioral diaries and performance rating halo and accuracy. North American Journal of Psychology $5(1): 81-90$.

137 O'Neal E (2005) Influence of future choice importance and arousal upon the halo effect. Integrative Physiological \& Behavioral Science 40(3):147-155.

138 Gizelis TI (2009) Gender empowerment and United Nations peacebuilding. Journal of Peace Research, 46(4):505-523.

139 Peeters G (1991) Evaluative inference in social cognition: The roles of direct versus indirect evaluation and positive-negative asymmetry: European Journal of Social Psychology, 21(2):131146.

140 Ryan MK, Haslam SA (2005a) The glass cliff: Evidence that women are over-represented in precarious leadership positions. British Journal of Management, 16(1):81-90.

141 Ryan MK, Haslam SA (2005b) The glass cliff: Implicit theories of leadership and gender and the precariousness of women's leadership positions. In Schyns, B., and Meindl, J. R., (eds), Implicit leadership theories: Essays and explorations Greenwich, CT: Information Age Publishing, 137160 .

142 Ryan MK, Haslam SA (2007a) The glass cliff: Exploring the dynamics surrounding the appointment of women precarious leadership positions. Academy of Management Review 32(1):549-572.
143 Ryan MK, Haslam SA (2007b) The glass cliff: The risks of being on top. CIPD Change Agenda London: CIPD.

144 Ryan MK, Haslam SA, Kulich C (2010) Politics and the glass cliff: Evidence that women are preferentially selected to contest hard-to-win seats. Psychology of Women Quarterly, 34(1):56-64.

145 Office for National Statistics (ONS) (April 2012) Labour market statistics [online] available at http://www.ons.gov.uk/ons/rel/lms/labour-marketstatistics/april-2012/statistical-bulletin.html retrieved 27th Jan 2012.

146 Adams R, Ferreira D (2009) 'Women in the Boardroom and Their Impact on Governance and Performance', Journal of Financial Economics, 94:291-309.

147 Blau FD, Kahn LM (2007) Changes in the labor supply behavior of married women: 1980-2000. Journal of Labor Economics, 25(3):393.

148 Kulich C, Trojanowski G, Ryan, MK, Haslam SA, Renneboog LDR (2011) Who gets the carrot and who gets the stick? Evidence of gender disparities in executive remuneration. Strategic Management Journal, 32(1):301-321.

149 Berne E (2010) Games people play: The psychology of human relationships. London: Penguin Books Ltd.

150 Peacock L (2012b) Listen up EU "many women don't want to work on boards" [online $23^{\text {rd }}$ Oct 2012] in the Telegraph available at http://www.telegraph.co.uk/finance/jobs/9626408/Li sten-up-EU-many-women-dont-want-to-work-onboards.html retrieved 28th Nov 2012.

151 Caul M (2001) Political parties and the adoption of candidate gender quotas: A cross-national analysis. Journal of Politics, 63(4):1214-1229.

152 Squires J (1996) Quotas for women: Fair representation? Parliamentary Affairs, 49(1):71-88.

153 Doldor E, Vinnicombe S, Gaughan M, Sealy R (2012) Gender diversity onboards: The appointment process and the role of executive search _rms. Technical report, Equality and Human Rights Commission Research Report Series, Manchester.

154 Hartnell CA, Ou AY, Kinicki A, (2011) Organizational culture and organizational effectiveness: A meta-analytic investigation of the competing values framework's theoretical suppositions. Journal of Applied Psychology, 96(4):694-706.

155 Inter Parliamentary Union (IPU) (Aug 2012) Of quotas, women's networks and mentors [online] available at http://www.airlineleader.com/thismonths-highlights/of-quotas-womens-networksand-mentors retrieved 20th Jan 2013

156 Abbott NG (2005) Linking values and organizational commitment: A correlational and experimental investigation in two organizations. 
Journal of Occupational and Organizational Psychology, 78(32):301-321.

157 Al-Kazi (2009) Decades-long struggle for women's rights Vital Voices [online] available from http://www.vitalvoices.org/desktopdefault.aspx?pag e_id=685 retrieved 30 th April 2012 .

158 Al-Lail H (2006) Muslim women between tradition and modernity: the Islamic perspective Journal of Muslim Minority Affairs, 16:99-111.

159 ABI (2012) Report on Board effectiveness: updating progress, promoting best practice, ABI, London.

160 Alimo-Metcalfe, B (1995) An investigation of female and male constructs of leadership and empowerment. Women in Management Review, 10(2):3-8.

161 Alimo-Metcalfe B, Alban-Metcalfe J (2005) The crucial role of leadership in meeting the challenges of change. Vision 9(2):27-39.

162 Allen E, Langowitz N, Minniti M (2007) The 2006 Global Entrepreneurship Monitor Special Topic Report: Women in entrepreneurship. Center for Women's Leadership Babson Park: Babson College NY.

163 Anderson D, Kelliher C (2009) Flexible working and engagement: The importance of choice. Strategic HR Review, 8(2):13-18.

164 Ayuso S, Argandoña A (2007) Responsible Corporate Governance: Towards a Stakeholder Board of Directors? (IESE Business School Working Paper No. 701). Retrieved May 14, 2010, from http://www.iese.edu/research/pdfs/DI-0701-E.pdf

165 Barney JB (1986) Organizational culture: Can it be a source of sustained competitive advantage? Academy of Management Review 11(3):656-665.

166 Becker BE, Cardy RL (1986) Influence of halo error on appraisal effectiveness: A conceptual and empirical reconsideration. Journal of Applied Psychology, 71(4):662-671.

167 Bilimoria D (2006) The relationship between women corporate directors and women corporate officers. Journal of Managerial Issues, 18(1):47-61.

168 Bintig A (1979) Bias in judging persons and bias measurement. Zeitschrift fur Experimentelle und Angewandte Psychologie, 26(2):181-197.

169 Bolman LG, Deal TE (1991) Leadership and management effectiveness: A multi-frame, multisector analysis. Human Resource Management, 30(9):509-534.

170 Catalyst (2007) 'The Bottom Line: Corporate performance and women's representation on boards', Catalyst, Available at http://www.catalyst.org/file/139/bottom\%20line\%20 2.pdf, Accessed [May 03 ${ }^{\text {rd }}$ 2013].
171 Catalyst 2011, The Bottom Line: Corporate Performance and Women's Representation on Boards (2004-2008), www.catalyst.org/file/445/the_bottom_line_corporat e_performance_and_women's_representation_on_bo ards_(2004-2008).pdf]

172 Campbell K, Minguez-Vera A (2008) Gender diversity in the boardroom and firm financial performance, Journal of Business Ethics, 83(3):435451.

173 Campbell K, Minguez Vera A (2010) Female board appointments and firm valuation: Short and longterm effects. Journal of Management and Governance, 14(1):37-59.

174 Deneulin, Severine, with Lila Shahani (2009) An Introduction to the Human Development and Capability Approach: Freedom and Agency. Sterling, VA: Earthscan.

175 Doepke M, Tertilt M (2011) Does female empowerment promote economic development?.

176 Fontanella-Khan J (2012) Sanctions to enforce female board quotas [online, $14^{\text {th }}$ Nov 2012] in the Financial Times available at http://www.ft.com/cms/s/0/4621efb6-2e80-11e29b98-00144feabdc0.html\#axzz2DVGnsrBG retrieved 28th Nov 2012.

177 Stein R, Cashman A (2009) Games at work - How to recognize and reduce office politics London: Jossey High-Pippert, A, \& Comer, 1998 Wiley.

178 Greene A, Kirton G (2011) The value of investigating stakeholder involvement. In Farnham, G.S., Diversity management. Diversity in the workplace: Multi-disciplinary and international perspectives Bristol: Gower.

179 Gries T, Naude WA (2010) Entrepreneurship and structural economic transformation. Small Business Economics Journal, 34(1):13-29.

180 Hummels D, Ishii J, Yi KM (2001) The Nature and Growth of Vertical Specialization in World Trade. Journal of International Economics, 75-96.

181 Hinkin TR (1995) A review of scale development practices in the study of organizations. Journal of Management, 21(5):967-988.

182 Hinkin TR, Schriesheim CA (1989) Development and application of new scales to measure the French and Raven (1959) bases of social power. Journal of Applied Psychology, 74(4):561-567.

183 Hladik M, (2012) Grass ceiling: Overhangs surge in female farmers [online] in Women's News available at

http://womensenews.org/story/entrepreneurship/120 919/grass-ceiling-overhangs-surge-in-femalefarmers retrieved 27th Nov 2012

184 Home Office Legislation (1970) The Equal Pay Act 1970 [online] available at http://www.legislation.gov.uk/ukpga/1970/41 retrieved 20th Jan 2013 
185 Home Office Legislation (2010) The Equality Act 2010 [online] available at http://www.legislation.gov.uk/ukpga/2010/15/conten ts retrieved 20th Jan 2013.

186 Horwitz FM, Chan TH, Quazi HA (2003) Finders, keepers? Attracting, motivating and retaining knowledge workers. Human Resource Management Journal, 13(4):23-44.

187 Jackson PR, Wall TD, Martin R, Davids K (1993) New measures of job control, cognitive demand and production responsibility. Journal of Applied Psychology, 78(1):753-762.

188 Karl M (1995) Women and Empowerment: Participation and Decision-Making London: Zed Books and the United Nations Non-Governmental Liaison Service.

189 Kark R, Waismel-Manor R, Shamir B (2012) Does valuing androgyny and femininity lead to a female advantage? The relationship between gender-role, transformational leadership and identification. The Leadership Quarterly, 23(3):620-640.

190 Kirsch C, Chelliah J, Parry W (2012) The impact of cross-cultural dynamics on change management. Cross Cultural Management: An International Journal, 19(2):166-195.

191 Knudsen K, Wærness K (2009) 19 Gender empowerment, economic development and spouses' housework in thirty-four countries. The International Social Survey Programme, 19842009: charting the globe, 378.

192 Kucinskas J (2010) A research note on Islam and gender egalitarianism: An examination of Egyptian and Saudi Arabian youth attitudes. Journal for the Scientific Study of Religion, 49(4):761-770.

193 Ackers P, Lincoln ND, Travers, Wilkinsom A (2002) The meaning of empowerment: The interdisciplinary etymology of a new management concept. International Journal of Management Reviews, 4(3):271-290.

194 Lyness KS, Thompson DE (1997) Above the glass ceiling ?: A comparison of matched samples of female and male executives. Journal of Applied Psychology 82(3):359-375.

195 McKinsey \& Company (2007) Gender Diversity, A Corporate Performance Driver', Women Matter, McKinsey \& Company.

196 McKinsey \& Company (2010a) 'Women leaders, a competitive edge in and after the crises', Women Matter 3, McKinsey \& Company.

197 McKinsey \& Company (2012b) 'Women at the Top of Corporations: Making it Happen', Women Matter 2010, McKinsey \& Company.

198 McDowell JM, Singell, LD, Ziliak JP (1999) Cracks in the glass ceiling: Gender and promotion in the economics profession. American Economic Review, 82(2):392-396

199 Nussbaum MC (2000) "Introduction," in Women and Human Development: The Capabilities Approach, pp. 1-33. Cambridge, UK: Cambridge University Press.

200 Nussbaum MC (2005) "Introduction," in Martha C. Nussbaum and Jonathan Glover, eds. Women, Culture, and Development: A Study of Human Capabilities, pp. 1-15. Oxford: Clarendon Press.

201 Naudé WA, Rossouw S (2010) Early international entrepreneurship in China: Extent and determinants. Journal of International Entrepreneurship, 8(1):87-111.

202 Neumayer E, De Soysa I (2011) Globalization and the empowerment of women: an analysis of spatial dependence via trade and foreign direct investment. World development, 39(7):1065-1075.

203 Peacock L (2012) We need female quotas because men aren't listening [online, $23^{\text {rd }}$ Oct 2012] in The Telegraph available http://www.telegraph.co.uk/women/womens business/9628429/We-need-female-board-quotasbecause-men-arent-listening.html retrieved 28th Nov 2012.

204 Reed M, (1996) 'Organizational Theorizing' In Clegg, S, Hardy C, Nord W, (eds), Handbook of Organization Studies. London: Sage.

205 Riggio R (1986) Assessment of basic social skills. Journal of Personality and Social Psychology, 51(3):649-660.

206 Ryan MK, Haslam SA (2006a) The glass cliff: The stress of working on the edge. European Business Forum, 27(1):42-47.

207 Ryan MK, Haslam, SA (2006b) What lies beyond the glass ceiling? The glass cliff and the potential precariousness of women's leadership positions. Human Resources Management International Digest, 14(1):3-5.

208 Ryan MK, Haslam, SA (2009) Glass cliffs are not so easily scaled: On the precariousness of female CEOs' positions. British Journal of Management, 20(1):13-16.

209 Ryan MK, Haslam SA, Hersby MD, Atkins C (2006) Women's potential, our passion: A survey of EMEA Women@Microsoft. Research report prepared for EMEA Microsoft March 2006 Exeter : Microsoft

210 Sayyed Mohsen Allameh, Marzieh Heydari, Sayyed Mohammad Reza Davoodi (2012) Studying the relationship between transformational leadership and psychological empowerment of teachers in Abade Township Procedia - Social and Behavioral Sciences, 31:224-230.

211 Supreme Council for Women in Bahrain, (SCW, 2010) Home [online] available at http://www.almoayedgroup.com/index.php?option=c 
om_content\&view $=$ article $\& i d=75 \&$ Itemid $=95$ retrieved 30 th April 2012

212 Skalli L (2011) Constructing Arab female leadership lessons from the Moroccan media. Gender \& Society, 25(4):473-495.

213 Sturges J, Guest D (2004) Working to live or living to work? Work/life balance early in the career. Human Resource Management Journal, 14(4):5-20.

214 Terjesen S, Sealy R, Singh C (2009) Women directors on corporate boards: A review and research agenda. Corporate Governance: An International Review, 17(3):320-337.

215 Tajfel H, Turner JC (1986) The social identity theory of intergroup behavior. In: Worchel, S. and Austin, W. G. (eds.) [Tajfel and tuner in (2009) women directors on corporate boards].

216 The Committee for Economic Development (CED), Fulfilling the Promise: How Women on Corporate Boards Would Make America and American Companies More Competitive, 2012.
217 United Nations (UN) (2010) Research Institute for Social Development: Combating Poverty and Inequality: Structural Change, Social Policy and Politics. Geneva: UNRISD "Gender Inequalities at Home and in the Market." Chapter 4, pp. 5-33.

218 Willmott H (1984) Images and ideals of managerial work: A critical examination of conceptual and empirical accounts. Journal of Management Studies, 21(3):349-368.

219 Willmott H (1993) Strength is ignorance; slavery is freedom: Managing culture in modern organizations. Journal of Management Studies, 30(4):515-552.

220 Yammarino FJ, Spangler WD, High-Pippert A, Comer BM (1993) Transformational leadership and performance: A longitudinal investigation. Leadership Quarterly, 4(1):81-102.

221 Zayani (2003) "Women and the Arab Economy: The Experience of Bahrain" Bahrain, Business Women's Association.

222 Zyoud (2007) The Problem of Single Women in the Arab World, Jordan. Amman. 